To be presented at the 1999 IESNA Annual Conference, August 1999, New Orleans, and to be published in the Proceedings. Submitted to the JIES for publication.

\title{
Comparison of Control Options in Private Offices in an Advanced Lighting Controls Testbed
}

\author{
Judith D. Jennings, Francis M. Rubinstein, Dennis DiBartolomeo \\ Building Technologies Department \\ Environmental Energy Technologies Division \\ Ernest Orlando Lawrence Berkeley National Laboratory \\ University of California \\ Berkeley, California, USA 94720 \\ Steven Blanc \\ Pacific Gas \& Electric Co. \\ Customer Energy Management Dept., Research \& Development Group \\ 2303 Camino Ramon, Suite 100 \\ San Ramon, California, USA 94583
}

April 1999

This work was supported by the General Services Administration, Pacific Rim Region, by the Pacific Gas \& Electric Co., and by the Assistant Secretary for Energy Efficiency and Renewable Energy, Office of Federal Energy Management Programs and Office of Building Technology, State and Community Programs, Office of Building Equipment of the U.S. Department of Energy under Contract No. DEAC03-76SF00098. 


\section{DISCLAIMER}

This report was prepared as an account of work sponsored by an agency of the United States Government. Neither the United States Government nor any agency thereof, nor any of their employees, make any warranty, express or implied, or assumes any legal liability or responsibility for the accuracy, completeness, or usefulness of any information, apparatus, product, or process disclosed, or represents that its use would not infringe privately owned rights. Reference herein to any specific commercial product, process, or service by trade name, trademark, manufacturer, or otherwise does not necessarily constitute or imply its endorsement, recommendation, or favoring by the United States Government or any agency thereof. The views and opinions of authors expressed herein do not necessarily state or reflect those of the United States Government or any agency thereof. 


\section{DISCLAIMER}

Portions of this document may be illegible in electronic image products. Images are produced from the best available original document. 


\title{
Comparison of Control Options in Private Offices in an Advanced Lighting Controls Testbed
}

\author{
Judith D. Jennings ${ }^{1}$, Francis M. Rubinstein ${ }^{1}$, Dennis DiBartolomeo', Steven L. Blanc ${ }^{2}$
}

\section{INTRODUCTION}

Lighting controls have the potential to reduce lighting energy consumption significantly and to moderate peak demand in commercial buildings [10],[7]. Lighting controls reduce lighting energy consumption by exploiting one or more lighting control strategies. The most common and, arguably, most successful lighting control strategy is occupant sensing, which employs an occupant sensor to switch lights on and off according to detected occupancy. Although occupant sensors are relatively common, there are surprisingly few well-documented studies in the US that demonstrate that they actually reduce lighting energy use sustainably [1],[2],[3]. Daylighting is another lighting control strategy that has been investigated in a few monitored sites [6],[7]. With the advent of inexpensive handheld remote controls, occupant-controlled manual dimming is becoming an affordable option, and has been shown to have some energy savings potential and high occupant satisfaction rating in one installation [2]. Less common strategies such as task tuning, lumen maintenance, and load shedding have been described in the literature [10] but not investigated at real installations. The most humble of lighting control strategies, bi-level switching, has not been seriously evaluated even in those states where it is required by energy code.

Given the many ways that lighting controls can reduce lighting energy waste and potentially improve occupant satisfaction, the shortage of well-monitored installations showing the sustained benefits of different lighting control strategies is surprising, and is probably a contributor to the relatively slow adoption of lighting controls in nonresidential buildings.

The lighting testbed in the Phillip Burton Federal Building in San Francisco was set up to fill many of these gaps in the understanding of savings achievable with lighting controls. Using data from a portion of the testbed, this paper focuses on the energy savings possible through use of occupancy, switching, and three types of dimming control in private offices, from very simple to complex intelligent systems.

\section{DESCRIPTION OF THE SITE}

The building used in this study is the Phillip Burton Federal Building in San Francisco. This 21-story high-rise office building was constructed in 1962 and has been undergoing major renovation as part of larger effort to modernize the building. About 85,000 net square feet (out of 180,000 gross square feet) on the $3^{\text {rd }}, 4^{\text {th }}$, and $5^{\text {th }}$ floors of the building were set aside as a testbed for examining the energy savings and cost-effectiveness of different types of lighting control systems in private offices, open daylit areas, and interior open office spaces. Each office or group of lights that are switched and controlled together is operated and monitored as a separate lighting zone, for a total of 175 zones. The three floors are entirely occupied by General Services Administration personnel, with tasks that vary widely and include administrative, architectural, real estate, legal, financial, and security personnel with a similar variety of working habits and schedules.

The 99 perimeter private office zones (with windows) on these three floors, accounting for 18,600 square feet, are the subject of this paper. These zones range in size from 112 to 480 square feet, with an average of 188 square feet. Single-glazed windows on all facades run from $3 \mathrm{ft}$. above the floor to ceiling height $(9$ $\mathrm{ft}$ ), and all are fitted with manually operated mini-blinds. The windows on the east, south, and west facades are coated with a film that absorbs approximately $50 \%$ of incident solar radiation (approximately $40 \%$ transmittance), while the north windows are uncoated (approximately $88 \%$ transmittance). Surrounding buildings shade the walls at the level of the $3^{\text {rd }}, 4^{\text {th }}$, and $5^{\text {th }}$ floors during parts of the day, and reflections off those buildings occasionally add to the daylight coming through the windows. A solar data collection station, which measures global and diffuse horizontal daylight illuminance on 5-min intervals, was installed on the roof of the building.

\footnotetext{
${ }^{1}$ Lawrence Berkeley National Laboratory

${ }^{2}$ Pacific Gas \& Electric Company
} 
Overhead electric lighting throughout the testbed consists primarily of 2' $X$ 4' 18-cell 3-lamp T-8 parabolic-louver fixtures, with some 2' X 2' 2-lamp fixtures. While task lighting is available everywhere in the open parts of the testbed, only perhaps $2 / 3$ of the private offices have task lighting of various types (fluorescent, incandescent, and halogen incandescent), some built-in (fluorescent under-shelf) and some brought in by the occupants. The most typical private office has two fixtures, but as many as six fixtures are found in the largest offices. After relamping and initial lamp burn-in at the start of the testbed, the average full-light illuminance in all private office spaces was about 800 lux, with a maximum of $1300 \mathrm{lux}$ and a minimum of 400 lux.

Though GSA buildings are not subject to the requirements of California's Title 24 energy code, the standard lighting control technique used throughout the Phillip Burton Federal building is bi-level switching. In this method one switch operates the center lamp in each fixture and another operates the outer lamps, resulting in 3 possible lighting levels despite the name "bi-level".

Plans of the experimental area are shown in Figure 1. Only the perimeter offices (shown unshaded) are discussed in the present paper. The arrows at the top of each of the three floor plans in the figure indicate where to look for each different area that we will discuss; for example, "5EP" indicates East Private daylit offices on the fifth floor. Shaded areas (described in the figure legend) will not be discussed in this paper.

\section{METHODS}

This installation, by its nature as a testbed, has a much more varied system of controls throughout its area than would be seen in an installation not subject to research. Each individual scenario that we examine, however, is representative of a technique that might be applied, on its own or in combination with few other control techniques, in any building. Of the thirteen separate control scenarios installed in the testbed, six are applied only to private offices, and five of these six are the focus of this paper. We will examine two primary lighting control techniques, occupant sensing and light level adjustment. Light level adjustment is further subdivided into bi-level switching, manual dimming, and two mears of automatic dimming in response to daylight. Previous work [4] has detailed the results from the open daylit zones under study in the testbed and future work will describe the results from additional control scenarios.

All fixtures on floors 3 and 5 were retrofitted with dimmable electronic ballasts and some means of controlling them. The bi-level switches were replaced with low-voltage electronic switches (with the appearance of an ordinary wall switch) that control all three lights together in order to simplify the dimming scenarios. Each private office on these floors is equipped with an occupant sensor. All lowvoltage switches and occupant sensors are connected to the distributed control system, so that each time the low-voltage switch is operated or the occupant sensor detects a change in occupancy, a switch event is automatically logged.

The entire fourth floor of the testbed serves as a reference or "base case" floor (we avoid calling it a "control" floor for obvious reasons), with the existing non-dimmable electronic ballasts and bi-level switching.

The underpinnings of the testbed consist of a distributed control system that acts as a data acquisition system throughout the testbed. Its minimum function is to collect trend data on energy use in each of the 175 zones in the testbed and in each whole quadrant of each of the three floors, as well as event data for each switch on the $3^{\text {rd }}$ and $5^{\text {th }}$ floors and every occupant sensor. The quadrant energy and demand monitoring also includes the non-testbed areas on the three floors. Switch and occupant sensor priorities are also programmed in the distributed control system.

For several of the control scenarios, the distributed control system also performs various control functions itself, relying for example on input from one or more light sensors to calculate a desirable ballast dimming level from a user-determined function and then transmitting that dimming response to the ballasts over the network. Among the private office scenarios, we programmed ballast control functions available in the distributed control system for two: the task tuning scenario and the indirect closed-loop scenario described below. 

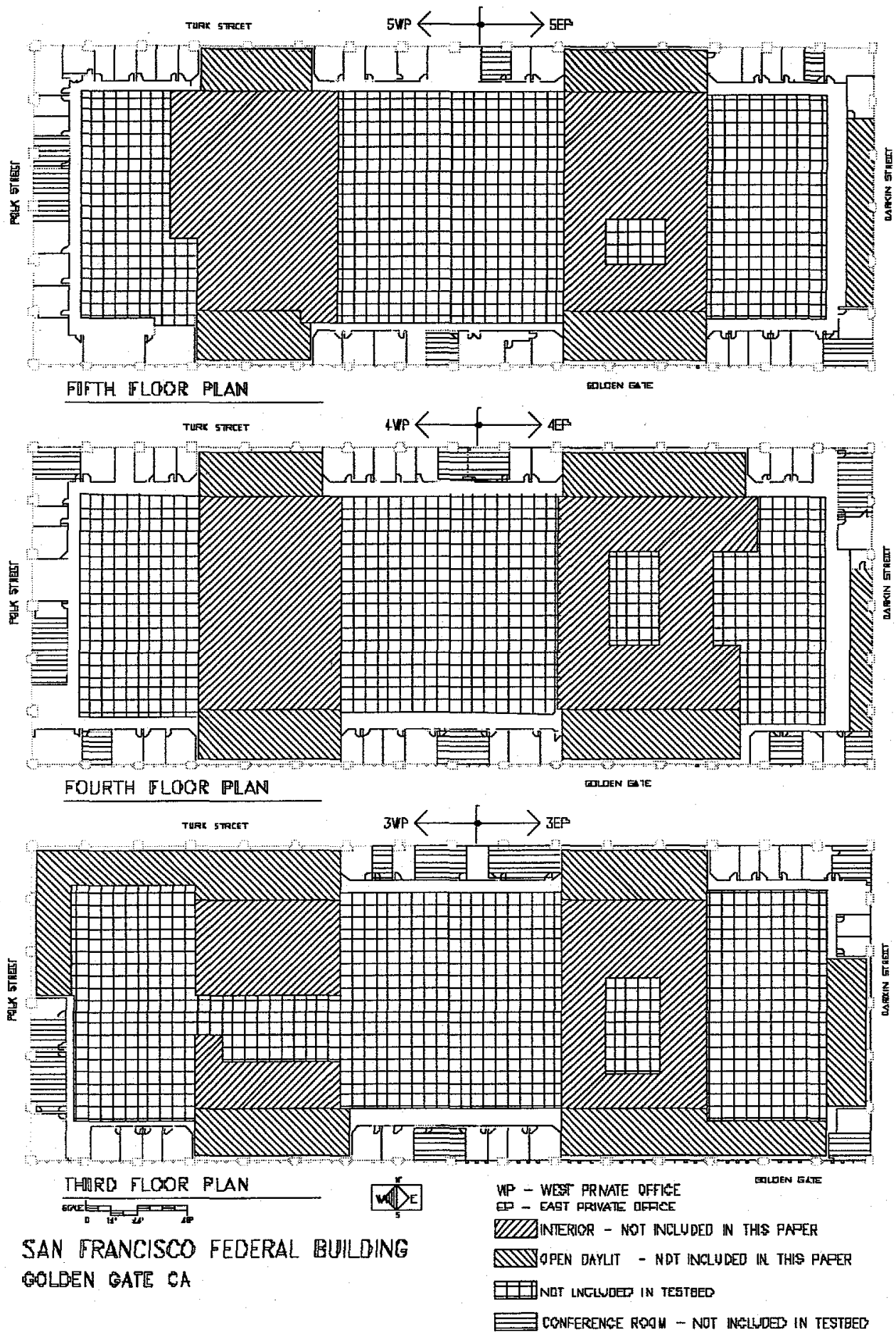

Figure 1. Floor plan of the Philip Burton Federal Building in San Francisco showing various portions of the testbed. 


\section{Scenarios Tested}

\section{Scenario 1: Bi-Level Switching}

The simplest scenario under study is the base case on the fourth floor (4EP and 4WP in Fig. 1), that uses the building standard bi-level switching. The switch state in these zones can be determined relatively accurately by monitoring energy use, because there is no dimming on the fourth floor. Occupancy is not monitored, though in hindsight it would have helped to monitor occupancy data for the base case zones.

To determine whether the occupants of the $4^{\text {th }}$ floor used their the bi-level switches to choose lower light levels, we analyzed the wall switch usage patterns for 30 daylit private offices. We used the measured energy data for each of the 30 offices to compute the average number of hours per day that the occupants set their lights to $1 / 3,2 / 3$ and full light levels.

\section{Scenario 2: Occupant Sensing With Task Tuning}

In the east half of the third floor (3EP in Fig. 1), lighting control in private offices is a combination of task tuning and occupant sensing. Task tuning refers to the practice of adjusting the workplane light level in overlit spaces either to a recommended level or to a level that is satisfactory to the occupants. (It differs from lumen maintenance in that its intent is to provide appropriate lighting, rather than to compensate for lamp lumen depreciation over time. Areas where task tuning is employed must also be readjusted periodically for lamp lumen depreciation.) The desired level may vary depending on the task performed in the lit area.

Before the spaces were occupied (June 1996), we used the distributed control system to tune the lights in the private offices on the east half of the $3^{\text {rd }}$ floor to provide between 550 and 660 lux $(50-60 \mathrm{fc})$. During the seven-month period of this analysis, the power to the lights was increased once to maintain the 550 660 lux light level in the space. No occupant control was provided, and the occupants were not told that their lights had been dimmed.

\section{Scenario 3: Occupant Sensing with Manual Dimming}

In the west half of the third floor ( $3 \mathrm{WP}$ in Fig. 1), lighting control in private offices is a combination of occupant sensing and manual dimming. Here the occupants can dim their lights using slide dimmers installed in addition to low-voltage wall switches. Turning off the switch at the bottom of the slide dimmer reduces the lights to the lowest level sachievable by the ballasts, leaving the lights obviously on. The occupants were not provided with instructions in the operation of the switches.

\section{Scenario 4: Occupant Sensing with Direct Closed-Loop Light Level Control}

The east half of the fifth floor is equipped with occupant sensors as usual, as well as ceiling-mounted closed-loop light sensors with a 60-degree field of view. The sensor signal is directly connected to the low-voltage control wiring of the dimmable ballasts in the room.. The light sensor is mounted in the closest possible ceiling tile above the work surface. Its output is calibrated by means of a hand-held illuminance meter.

\section{Scenario 5: Occupant Sensing with Indirect Closed-Loop Light Level Control}

The west half of the fifth floor also has closed-loop light sensors, but differs from the east half in that the light sensor output is used as one input to a ballast control function in the distributed control system. The output from that function in turn controls the ballasts. The ballast control function is programmed into the system by the operator, and can be tuned to the specific needs of the occupants.

\section{Culling the Data}

In this paper we analyze in detail approximately 7 months (June 1 - December 31,1998 ) of overhead lighting data in private offices on weekdays.

Our method of determining energy savings requires not only the lighting energy data but also the wall switch and occupant sensor data for each analyzed office. Therefore, we had to exclude a number of rooms from the analysis simply because not all three data streams were successfully recorded over the seven- 
month analysis period. Also, some GSA working groups were moved from one area to another during the test period, leaving some areas largely unoccupied. We eliminated entire zones from further consideration if substantial data (more than 150 out the 214 possible days from June through December) was missing or if our analysis of occupant sensor data showed that the zone was largely unoccupied over the test period. This first level filter removed 4 out of 25 possible private offices on the third floor and 41 of 55 private offices on the $5^{\text {th }}$ floor, leaving 21 zones on the $3^{\text {rd }}$ floor and only 14 zones on the $5^{\text {th }}$ floor. This first filter left us with 4494 zone-days for the $213^{\text {rd }}$ floor zones and 2996 zone-days for the $145^{\text {th }}$ floor zones.

Next, we applied a second filter to the 39 remaining offices in order to reject zone-days that we deemed to be substantially unoccupied. The second filter rejected days when either

- the total time the lights were on was less than one hour, or

- the occupants used no overhead lights AND occupancy data showed less than 4.5 occupied hours.

The latter condition was intended to include those days where the occupant apparently worked all day without overhead lights. A total of 2058 zone-days survived the second filter (substantial occupancy) on the third floor, and 1410 survived on the $5^{\text {th }}$ floor. Thus, an average of 98 occupied days were considered for each of the 21 sampled offices on the $3^{\text {rd }}$ floor during the period from June 1 - December 31,1998 , while an average of 101 occupied days were examined for the 14 sampled offices on the $5^{\text {th }}$ floor. Most of the data set from the direct closed-loop daylighting systems on the east half of the $5^{\text {th }}$ floor did not survive the filters for this seven-month period.

30 offices on the fourth floor survived the first filter. The second filter did not apply in the same way, because we had no occupancy data, but zone-days where no lighting was used were considered unoccupied and were not used in the analysis.

\section{Occupant Sensors, Dimming, and the Moving Baseline}

Occupant sensors throughout the study are commissioned to turn lights off when no occupancy has been detected for approximately 15-20 minutes ${ }^{3}$. Wall switches are programmed to have priority over occupant sensors, so that if an occupant wishes his/her lights to stay off, s/he can turn the wall switch to the "off" position. However, even with the wall switch set to the "off" position, the occupant sensors continue to log occupancy.

Each time an office occupant turns his/her wall switch on or off, the time, date and switch state (ON or OFF) are automatically recorded. Each time the occupant sensor data indicats a change in the occupancy of the space, the time, date and occupancy state (occupied or vacant) are recorded. Wall switch and occupant sensor operation times are recorded as event data with one-minute resolution. Energy data are recorded automatically every 15 minutes in each zone.

To exploit the unprecedented detail of information provided by these data, we developed a computational method to analyze the wall switch and occupancy data. With this approach, we could determine, to within a minute, when the lighting controls in each office were in one of the four possible states defined in Table 1 below:

\footnotetext{
${ }^{3}$ The 15 to 20 -minute time delay was set for the occupant sensors in order to minimize occupant complaints, based on the experience of some of the project participants. We believe that a 10-minute delay is more commonly used, and would certainly increase energy savings. False "off" problems can be addressed more effectively with improved sensitivity and placement of occupant sensors, possible with more knowledgeable installers or a more carefully executed job.
} 
Table 1.

Lighting Use State Definitions

\begin{tabular}{c|lccc}
\hline State & \multicolumn{1}{|c}{ Description } & $\begin{array}{c}\text { Wall } \\
\text { Switch }\end{array}$ & $\begin{array}{c}\text { Occupant } \\
\text { Sensor }\end{array}$ & $\begin{array}{c}\text { Overhead Light } \\
\text { State }\end{array}$ \\
\hline 0 & Office vacant with light switch OFF & OFF & OFF (vacant) & OFF \\
1 & Office occupied with light switch OFF & OFF & $\begin{array}{c}\text { ON } \\
\text { (occupied) }\end{array}$ & OFF \\
2 & Office vacant with light switch ON & ON & OFF (vacant) & OFF \\
3 & Office occupied with light switch ON & ON & $\begin{array}{c}\text { ON } \\
\text { (occupied) }\end{array}$ & ON \\
\hline
\end{tabular}

An office can only be in one state at a time although it is common for an office to pass frequently from state to state over the course of a day. Figure 2 is a lighting energy plot from a typical monitored office. The lower trace shows actual lighting energy use, directly measured at 15-minute intervals. The superimposed upper traces show when the wall switch and occupant sensor switched the lights ON or OFF. The duration of each resultant state can also be seen in the figure. As expected, the State 2 vacancy "notches" in the occupant sensor trace align with the "power off" portions of the overhead lighting energy data. These dips in the power data reflect what we would expect based solely on the wall switch and occupancy data (the small blips at the bottom are noise).

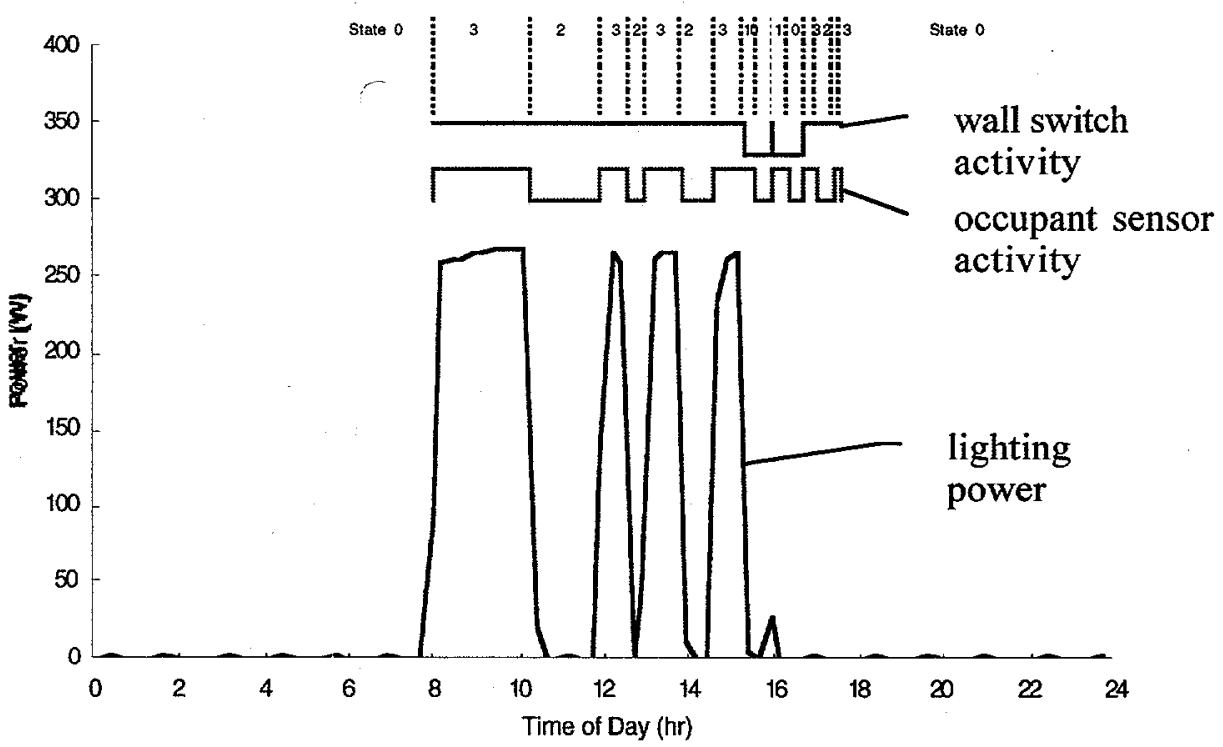

Figure 2. Lighting power, wall switch operation and occupant sensor operation as a function of time of day for a typical private office on the third floor. The resultant lighting use states are marked above the graph.

Using the state definitions, we can calculate several quantities of interest to evaluating lighting operation hours (all calculations assume a wall switch):

$$
\text { Measured (actual) lighting ON hours = Time in state } 3
$$

Calculated lighting ON hours for wall switch only $=$ Time in state $3+$ Time in state 2

$$
\text { Energy use for wall switch only }=(\text { Time in state } 2+\text { Time in state } 3) * \text { installed wattage }
$$

The energy use for wall switch only for each zone-day is used as the normalization constant for the occupant sensor and dimming energy use values (see Results). 
As an indicator of occupant sensor effectiveness, state 2 is of the greatest interest since the occupant sensor can only reduce lighting hours by the length of time that the lights are in this state. We define the energy savings from an occupant sensor to be:

\section{Daily Energy Savings $(\%)=$ Time in State $2 \div$ (Time in state $2+$ Time in state 3 )}

Although we have no zones that use occupant sensing alone as a control technique, we can calculate the full-light energy use with occupant sensing alone:

\section{Energy use with occupant sensing alone $=$ Time in state $3 *$ installed wattage}

Similarly, the effects of the occupant sensor data can be deconvolved roughly from the energy data to give us an estimate of the energy that would have been used over the wall switch ON hours with dimming only and no occupant sensor:

Energy use with dimming alone $=$ Energy data $*($ Time in state $2+$ Time in state 3$) \div($ Time in state 3$)$

These values are computed for each doy and office in the data set, effectively providing a tailored or "moving" baseline for each individual office. While cumbersome, this method provides far more accurate information about how occupancy patterns affect lighting usage than the standard method of using a fixed number of hours as an assumed daily average, though it results in lower energy savings. In particular, it allows one to explore how the typical variations in people's working habits affect the occupant sensor effectiveness from day to day.

The moving-baseline method for analyzing the savings from lighting controls is nothing more than a formalization of the methods that some occupant sensor manufacturers now use to demonstrate the effectiveness of these controls for specific building applications. [1] and [3] report using a similar technique.

\section{RESULTS}

\section{Occupant sensors}

Figure 3 shows the lighting energy data for a typical office with an occupant sensor for four different days in the month of May 1998. The wall switch ON and OFF times and the vacancy and occupancy as indicated by the occupant sensor are superimposed on the same graphs, as in Figure 2.

The electric power usage for each day reflects the occupancy pattern recorded by the occupant sensor for that day, and illustrates how much energy the occupant sensor actually saves. Consider Fig $3 b$, where the energy savings from occupant sensing are a modest $7 \%$ since the occupant apparently left the office only once at noon. On the other days (Fig. 3a, 3c, and 3d), the occupant was out of the office for longer times thus increasing the occupant sensor savings for these days to $28-37 \%$. Note that the long time delay settings on the occupant sensors distort the occupancy data to an extent that varies depending on the habits of the occupant. An occupant who stays in his/her office all day will have fairly accurate occupancy readings. An occupant who comes in for one minute every 15 minutes can show a similar occupancy pattern without being present more than a few accumulated minutes during the day.

Table 2 gives statistics for the third and fifth floor offices with occupant sensors. 

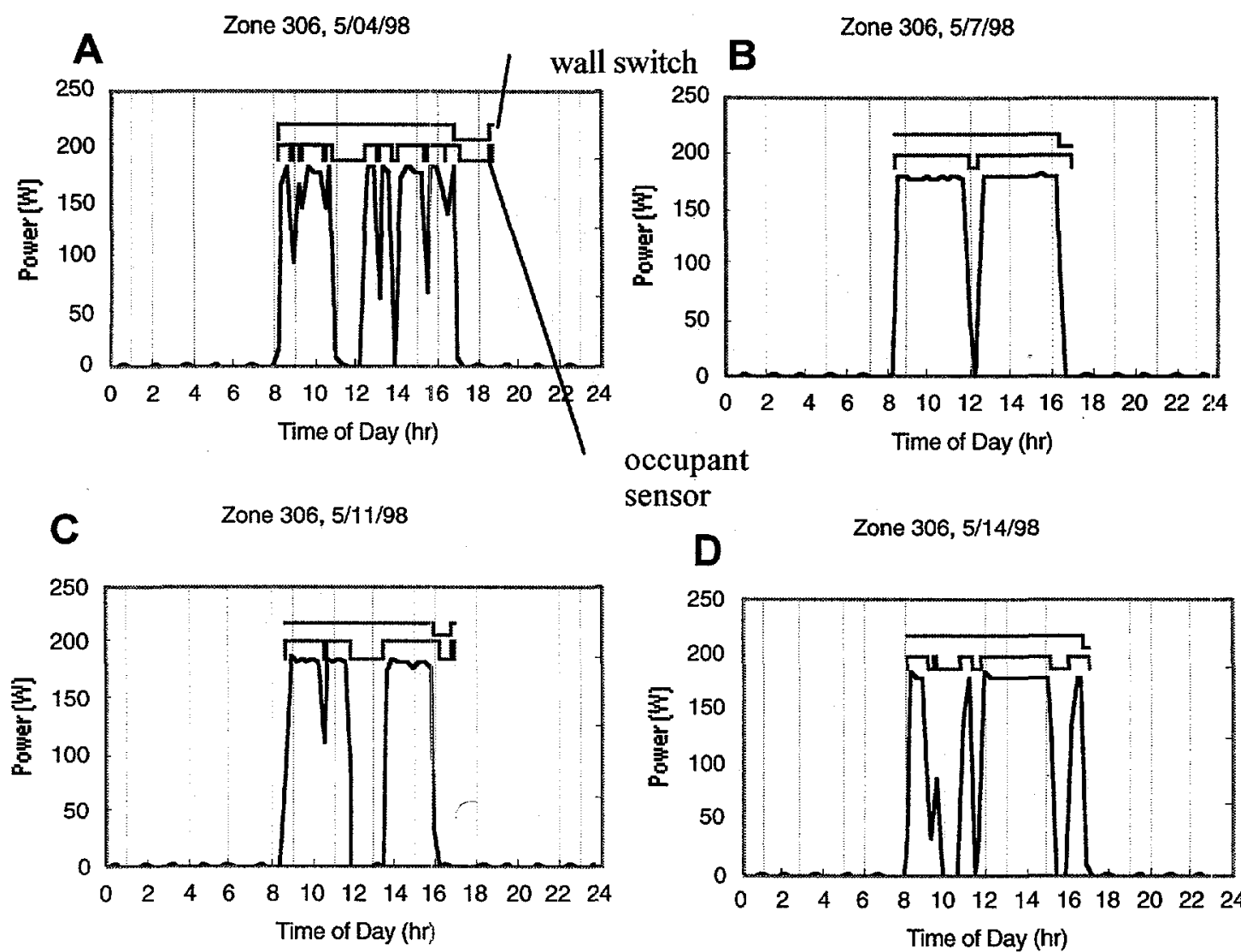

sensor

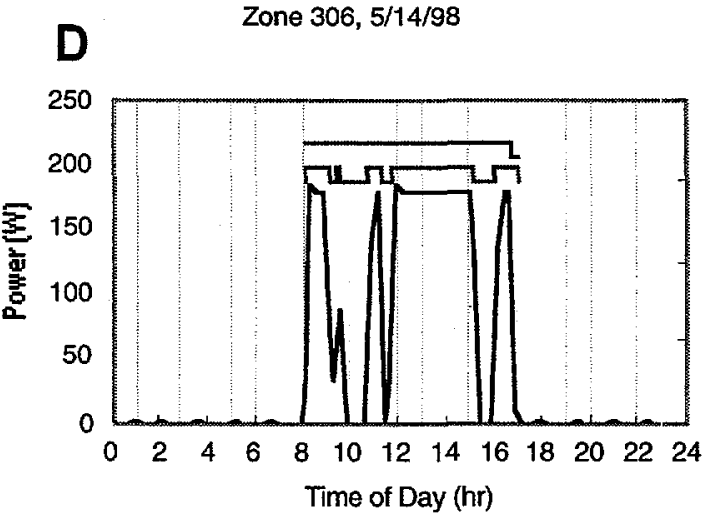

Figure 3. Lighting energy use, wall switch and occupant sensor operation as a function of time of day for one typical private office for four different weekdays in May 1998. (A) May 4, (B) May 7, (C) May 11 and (D) May 14, 1998. 
Table 2: Third and Fifth Floor Lighting Data

\begin{tabular}{|c|c|c|c|c|c|c|c|c|c|}
\hline \multirow[t]{2}{*}{ Zone } & \multicolumn{3}{|c|}{ Energy savings } & \multicolumn{2}{|c|}{$\begin{array}{c}\text { Measured occupied } \\
\text { hours }\end{array}$} & \multicolumn{2}{|c|}{$\begin{array}{l}\text { Measured wall switch } \\
\text { ON hours }\end{array}$} & \multicolumn{2}{|c|}{$\begin{array}{c}\text { Measured Lighting } \\
\text { ON hours }\end{array}$} \\
\hline & $\begin{array}{l}\text { Number } \\
\text { of days }\end{array}$ & $\frac{\text { Average }}{(\%)}$ & $\frac{\text { Stdev }}{(\%)}$ & $\frac{\text { Average }}{\text { (hr/day) }}$ & Stdev & $\begin{array}{l}\text { Average } \\
\text { (hr/dav) }\end{array}$ & Stdev & $\frac{\text { Average }}{\text { (hr/day) }}$ & Stdev \\
\hline 306 & 93 & $20.53 \%$ & $15.98 \%$ & 7.05 & 1.64 & 8.22 & 1.24 & 6.52 & 1.63 \\
\hline 307 & 111 & $20.61 \%$ & $17.63 \%$ & 7.31 & 2.14 & 8.62 & 3.08 & 6.71 & 2.75 \\
\hline 309 & 85 & $17.00 \%$ & $11.84 \%$ & 7.54 & 2.02 & 8.32 & 2.17 & 6.94 & 2.13 \\
\hline 310 & 72 & $16.79 \%$ & $13.50 \%$ & 6.90 & 1.81 & 7.56 & 1.97 & 6.28 & 1.90 \\
\hline 316 & 103 & $2.67 \%$ & $8.67 \%$ & 8.56 & 2.53 & 7.24 & 2.98 & 6.98 & 2.74 \\
\hline 317 & 103 & $36.69 \%$ & $13.09 \%$ & 6.49 & 1.37 & 9.96 & 1.92 & 6.21 & 1.51 \\
\hline 318 & 95 & $24.75 \%$ & $14.95 \%$ & 7.73 & 1.58 & 9.58 & 2.30 & 7.10 & 1.92 \\
\hline 329 & 125 & $7.42 \%$ & $13.25 \%$ & 9.94 & 3.09 & 6.42 & 4.71 & 5.69 & 4.22 \\
\hline 338 & 93 & $17.62 \%$ & $11.48 \%$ & 7.11 & 1.94 & 8.31 & 2.29 & 6.78 & 2.05 \\
\hline 339 & 97 & $27.78 \%$ & $15.71 \%$ & 8.08 & 2.13 & 9.91 & 2.53 & 7.09 & 2.24 \\
\hline 340 & 123 & $14.17 \%$ & $10.41 \%$ & 11.34 & 1.42 & 12.75 & 2.27 & 10.82 & 1.44 \\
\hline 341 & 120 & $28.72 \%$ & $21.89 \%$ & 7.40 & 2.45 & 9.28 & 2.68 & 6.43 & 2.60 \\
\hline 342 & 87 & $13.67 \%$ & $15.47 \%$ & 8.33 & 2.06 & 8.07 & 2.97 & 6.83 & 2.69 \\
\hline 343 & 108 & $20.31 \%$ & $11.84 \%$ & 7.69 & 1.17 & 8.09 & 1.93 & 6.33 & 1.50 \\
\hline 344 & 96 & $23.40 \%$ & $20.14 \%$ & 7.59 & 1.78 & 6.95 & 5.04 & 4.52 & 3.35 \\
\hline 345 & 102 & $32.62 \%$ & $15.59 \%$ & 7.99 & 1.78 & 10.88 & 2.74 & 7.20 & 2.22 \\
\hline 346 & 82 & $19.71 \%$ & $15.08 \%$ & 7.58 & 1.42 & 7.32 & 3.30 & 5.64 & 2.46 \\
\hline 347 & 79 & $25.37 \%$ & $17.81 \%$ & 7.21 & 2.07 & 8.63 & 3.07 & 6.31 & 2.41 \\
\hline 348 & 88 & $20.50 \%$ & $17.34 \%$ & -8.53 & 2.46 & 10.14 & 3.73 & 7.80 & 2.98 \\
\hline 349 & 69 & $34.90 \%$ & $14.52 \%$ & 6.57 & 1.76 & 9.42 & 3.01 & 5.92 & 2.02 \\
\hline 350 & 127 & $4.69 \%$ & $12.55 \%$ & 10.52 & 3.38 & 6.77 & 3.84 & 6.39 & 3.75 \\
\hline 513 & 96 & $12.06 \%$ & $11.94 \%$ & 6.84 & 2.22 & 5.64 & 3.24 & 4.85 & 2.86 \\
\hline 514 & 85 & $11.05 \%$ & $13.28 \%$ & 7.10 & 2.53 & 6.08 & 3.34 & 5.36 & 3.12 \\
\hline 515 & 69 & $14.71 \%$ & $14.39 \%$ & 8.29 & 2.36 & 9.20 & 2.32 & 7.90 & 2.44 \\
\hline 516 & 96 & $20.24 \%$ & $10.58 \%$ & 8.43 & 2.04 & 9.29 & 2.15 & 7.41 & 2.16 \\
\hline 517 & 104 & $14.77 \%$ & $12.35 \%$ & 7.59 & 2.39 & 8.59 & 2.74 & 7.23 & 2.44 \\
\hline 518 & 88 & $15.40 \%$ & $15.54 \%$ & 7.36 & 2.15 & 8.45 & 2.18 & 7.11 & 2.15 \\
\hline 520 & 88 & $12.66 \%$ & $12.95 \%$ & 7.76 & 1.86 & 8.09 & 2.23 & 7.06 & 2.20 \\
\hline 522 & 120 & $13.99 \%$ & $13.08 \%$ & 8.62 & 1.47 & 8.68 & 1.91 & 7.45 & 1.98 \\
\hline 525 & 116 & $27.66 \%$ & $22.37 \%$ & 7.26 & 2.64 & 8.83 & 1.80 & 6.50 & 2.51 \\
\hline 526 & 116 & $49.85 \%$ & $23.53 \%$ & 5.77 & 2.70 & 11.10 & 3.80 & 5.22 & 2.87 \\
\hline 527 & 121 & $24.28 \%$ & $26.22 \%$ & 8.10 & 2.78 & 10.26 & 2.22 & 7.62 & 2.72 \\
\hline 528 & 111 & $23.18 \%$ & $23.50 \%$ & 9.11 & 2.94 & 9.32 & 5.03 & 6.67 & 3.91 \\
\hline 529 & 116 & $41.17 \%$ & $22.87 \%$ & 7.54 & 3.58 & 12.20 & 2.75 & 7.51 & 3.59 \\
\hline 535 & 84 & $21.24 \%$ & $27.84 \%$ & 8.31 & 3.31 & 9.55 & 3.56 & 7.37 & 3.59 \\
\hline
\end{tabular}

Keeping in mind the time delay settings of the occupant sensors, we further analyzed the computed state data to compare lighting usage and occupancy trends in individual offices. In Figure 4 the dots show the average measured lighting ON hours per day (both occupant sensor and switch $\mathrm{ON}$ ) for each of the 21 offices on the $3^{\text {rd }}$ floor. Superimposed on the same figure are the lighting ON hours calculated based on recorded wall switch operation only (as though there were no occupant sensors), shown as small circles. In most cases, the occupant sensor-plus-switch data show fewer lighting ON hours by about 2 hours per day than the switch data alone. Finally, the dashes on the same graph show the apparent occupied hours as recorded by the occupant sensor alone, without regard to whether the lights are on or not. Figure 5 shows similar data for each of the 14 offices on the $5^{\text {th }}$ floor. Those zones where the apparent occupied hours are above the calculated (wall switch) $\mathrm{ON}$ hours (Fig.4: rooms 2, 3, 4, 11, 12; Fig. 5; rooms 12, $13,14)$ are occupied by individuals who sometimes occupy their daylit offices without switching on the overhead lights. The average of all rooms on the floor is shown at the far right-hand side of each figure. 


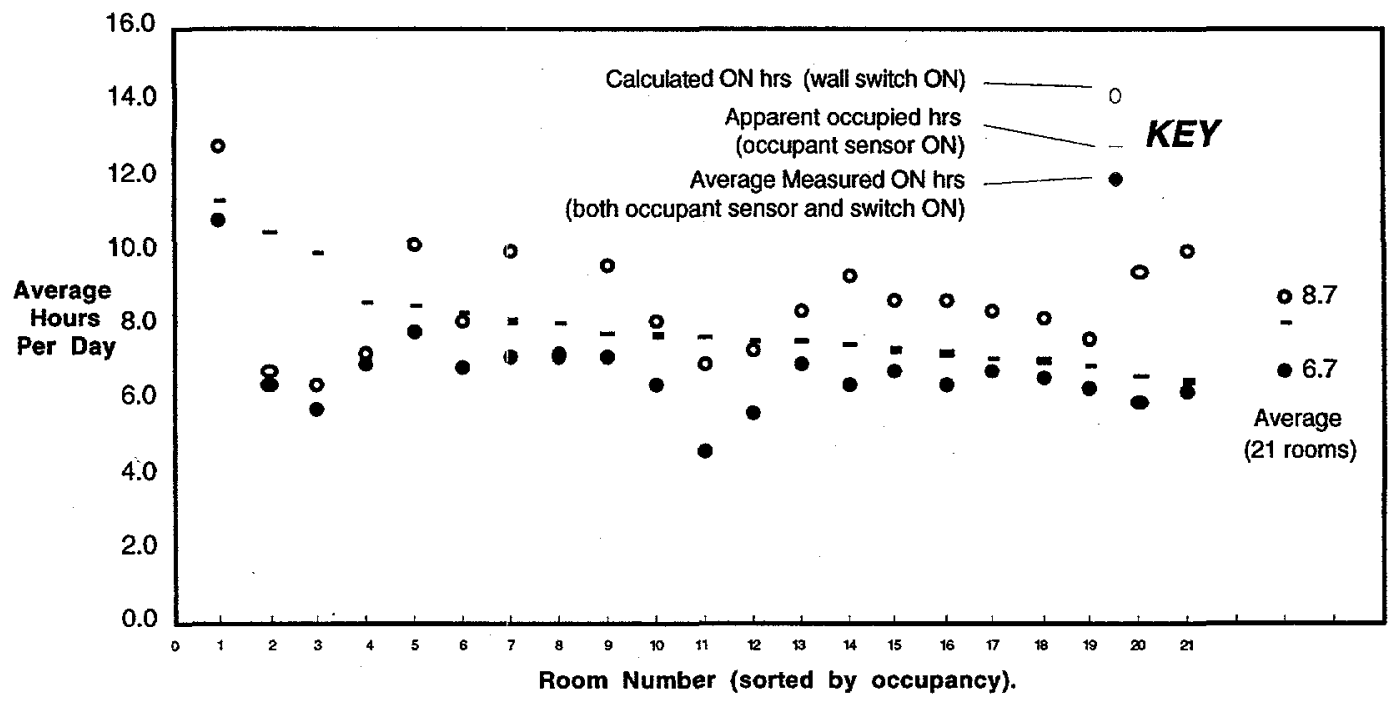

Figure 4. Average hours per day that lighting is $\mathrm{ON}$ as measured using occupant sensor control and as calculated based on wall switch use only for 21 offices on the $3^{\text {rd }}$ floor. Data are for occupied weekdays from June 1 to December 31, 1998.

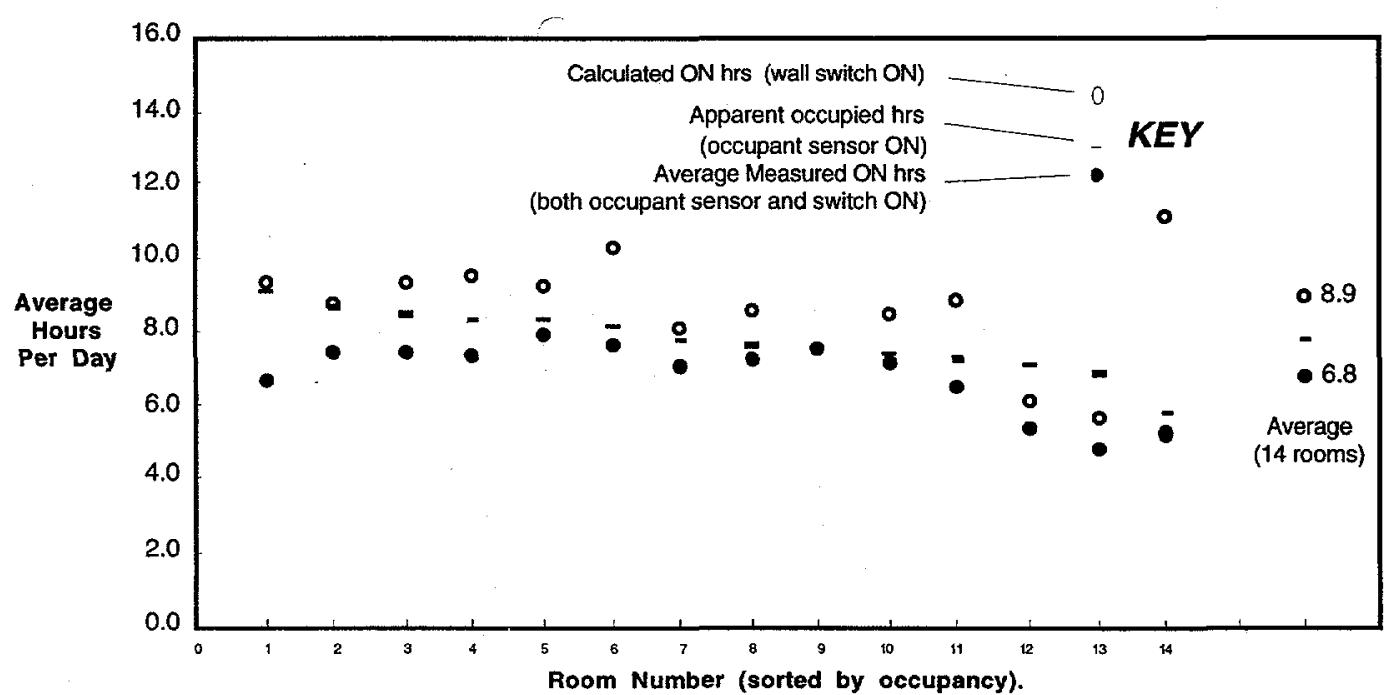

Figure 5. Average hours per day that lighting is ON as measured using occupant sensor control and as calculated based on wall switch use only for 14 offices on the $5^{\text {th }}$ floor. Data are for occupied weekdays from June 1 to December 31, 1998.

Finally, to develop a picture of the energy savings over the entire office sample for the seven-month period, we calculated the percentage daily energy savings for all of the offices and sorted the resulting values into 20 bins at intervals of $5 \%$ (the bins are ranges of energy savings: i.e., $0-5 \%$ energy savings, $5-10 \%$, etc.) with one extra bin ( $0 \%)$ to capture all those zone-days when there was no energy savings ${ }^{4}$. This probability distribution of calculated energy savings values for the entire 7 -month period is presented in Figure 6 for the 21 offices on the third floor, and Figure 7 for the 14 offices on the $5^{\text {th }}$ floor.

\footnotetext{
${ }^{4}$ The $0 \%$ bin contains only zone-days with exactly zero energy savings. The $0-5 \%$ bin includes zonedays with greater than zero and less than or equal to $5 \%$ energy savings, etc.
} 


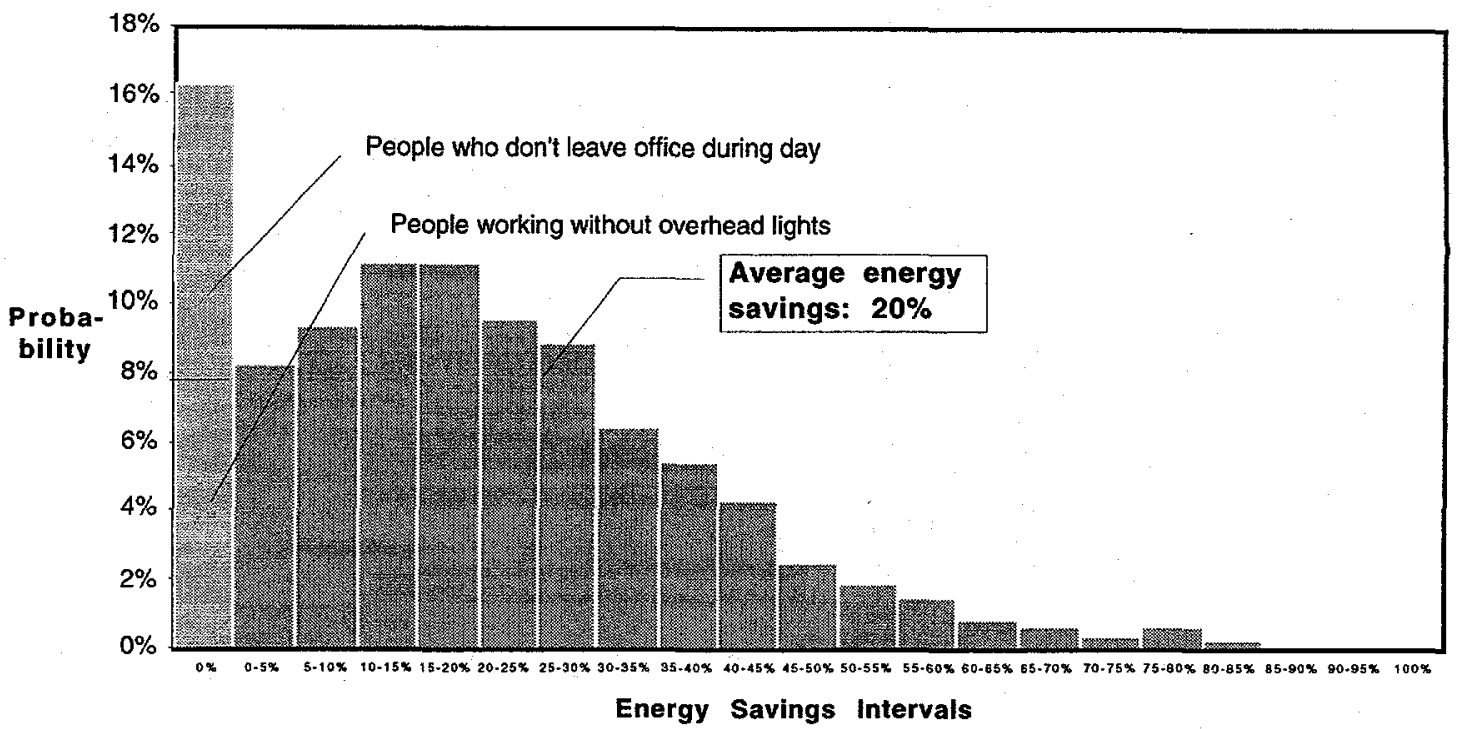

Figure 6. The energy savings from occupant sensors in 21 offices on the $3^{\text {sd }}$ floor for occupied days between June 1 and December 31, 1998. The energy savings by zone-day are binned into $5 \%$ intervals with a separate bin for $0 \%$ energy saving days.

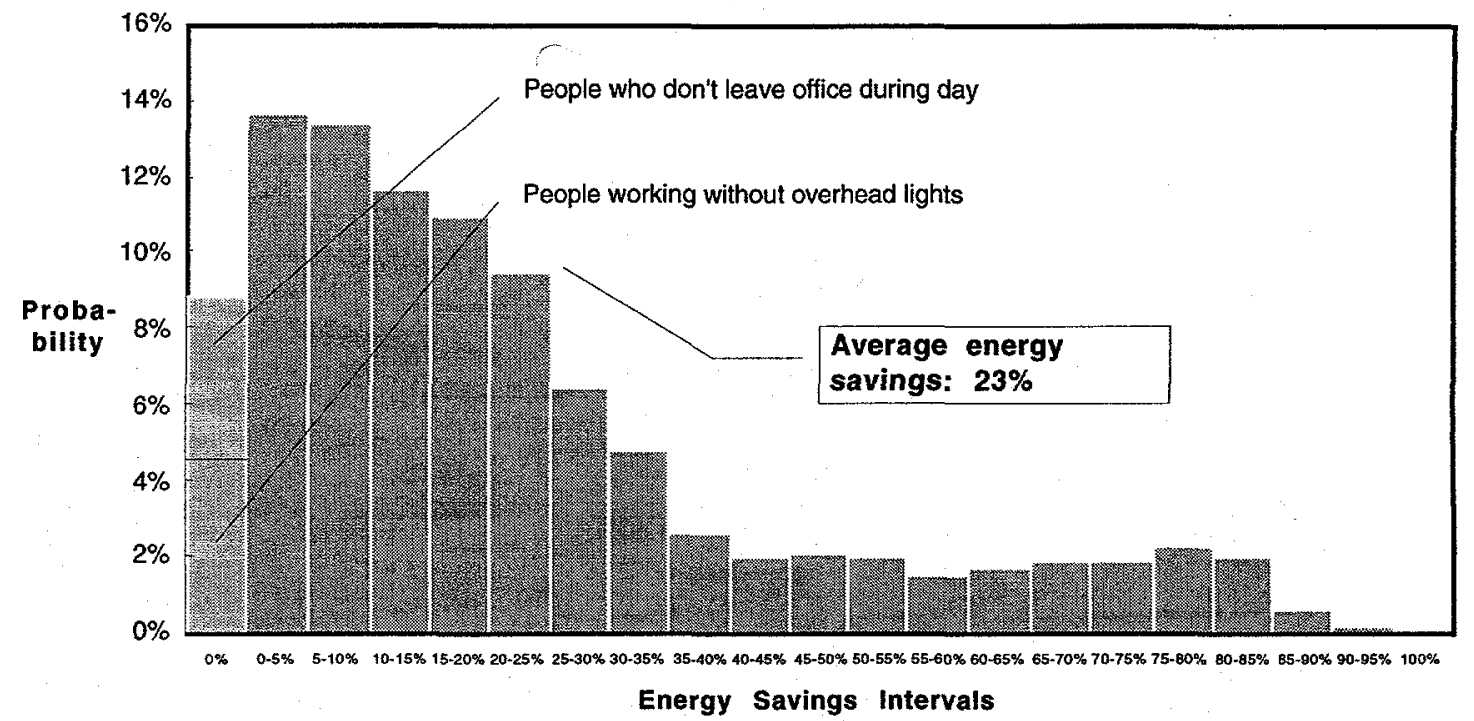

Figure 7. The daily energy savings from occupant sensors in 14 offices on the $5^{\text {th }}$ floor for occupied days between June 1 and December 31, 1998. The energy savings by zone-day are binned into $5 \%$ intervals with a separate bin for days with exactly $0 \%$ energy savings.

Figure 6 shows, for example, that on the third floor there is about an $11 \%$ probability that occupant sensors will save between 10 and $15 \%$ of overhead lighting energy on a given day, and almost a $2 \%$ probability that they will save between 55 and $60 \%$. Figures 6 and 7 imply that the energy savings from occupant sensors in a group of offices is not a single value but rather a probabilistic distribution function that reflects the fact that the actual energy savings varies from day to day and office to office.

Note that the most likely energy savings bin (or interval) is $15-20 \%$ on the $3^{\text {rd }}$ floor (Fig. 6) with an average energy savings of $20 \%$. For the $5^{\text {th }}$ floor (Fig. 7), occupant behavior seems to vary from day to day more than on the third floor. While the probability of obtaining large energy savings (e.g. $>50 \%$ ) is higher than for the $3^{\text {rd }}$ floor, $0-5 \%$ is the most likely energy savings bin, and the average energy savings 
is about $23 \%$. The average energy savings noted on both figures includes the effect of those days for which there was $0 \%$ energy savings 5 .

Another way to look at the energy savings from occupant sensors is to add up the lighting ON time by zone-day, sort the results into time-period bins on the x-axis, and plot the probability of each bin (e.g. 1 $\mathrm{hr} /$ day, $2 \mathrm{hrs} /$ zone-day, ..., $8 \mathrm{hrs} / \mathrm{zone}$-day, ..., $24 \mathrm{hrs} /$ zone-day) on the y-axis. This type of analysis is shown in Figures 8-9 for the $3^{\text {rd }}$ floor and Figures 10-11 for the $5^{\text {th }}$ floor. The data are normalized so that the sum of all the values equals $100 \%$ (i.e., the lights must be on for some period each day even if this period is zero). In all four of these figures the apparent occupancy (occupant sensor bin data) appears as gray bars behind the lighting ON hours data. The white bars in Figs. 8 and 10 represent lighting ON hours calculated from the wall switch data alone. Note that in the absence of the occupant sensor, the lights are quite likely to be on for 9-10 hours per day, and are often on as long as 12 hours. Furthermore, the peak of this profile is shifted to the right of the peak of the occupancy profile, which occurs at 8-9 hours day. With the hours of operation reduced by the occupant sensor (black bars in Figs. 9 and 11), lighting ON hours peak at only 7-8 hours per day. This is perhaps the clearest evidence that the occupant sensors reduced hours of lighting operation effectively, causing the lighting schedule to align better with actual occupancy.

It is important to note that the cleaning crews in the building are well trained to turn off lights consistently as they make their rounds through the building at night. In some cases, such as an occupant leaving his/her door locked with the light switch on, the occupant sensor is indeed responsible for the overnight savings. We had no reliable means to keep track of such hours and did not include them in the analysis. Similarly we did not count hours where the light switch was left on all day in an unoccupied office but the lights were turned off by the occupant sensor.

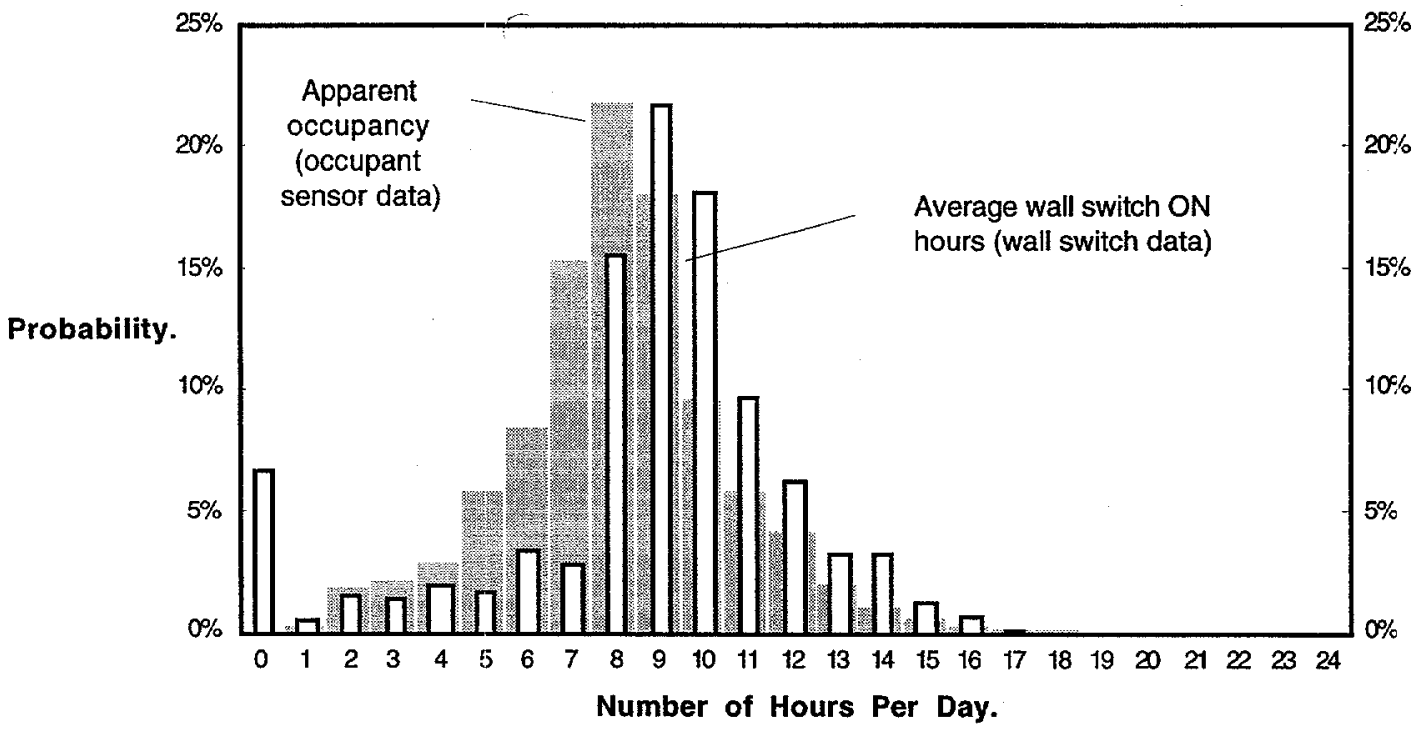

Figure 8. Average lighting ON hours per day (calculated from the wall switch data) for 21 offices on the $3^{\text {ro }}$ floor for occupied days between June 1 and December 31, 1998. Apparent occupancy (occupant sensor data) for the same data set is shown with gray bars. The apparent occupancy includes the occupant sensor time delays and therefore overestimates actual occupancy.

\footnotetext{
${ }^{5}$ Two very different circumstances result in zero energy savings from occupant sensors: for individuals who never leave their offices during the day, the sensor never turns off the lights and thus saves no energy. For individuals who work without overhead lights, the operation of the occupant sensor has no effect.
} 


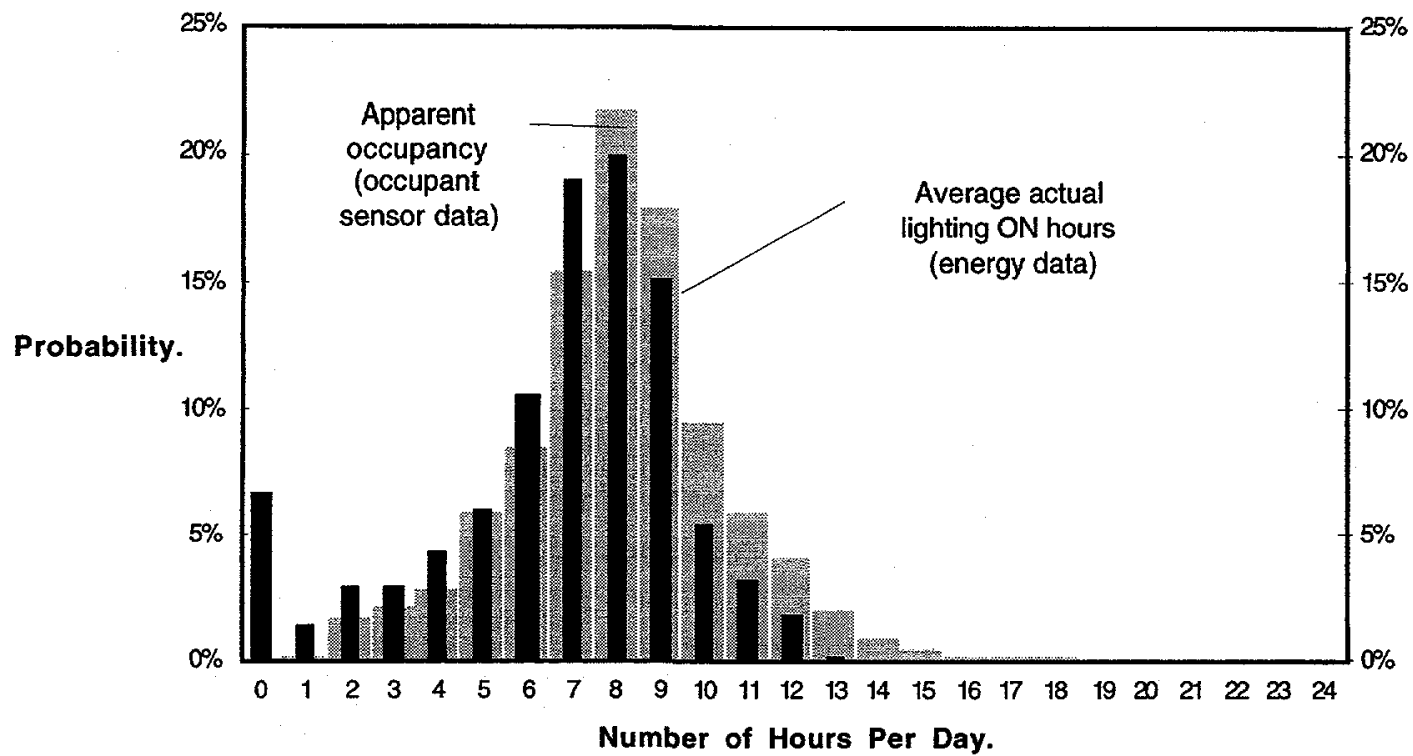

Figure 9. Average lighting ON hours per day for the $213^{\text {rd }}$ floor offices (both light switch and occupant sensor $O N$ ) for occupied days between June 1 and December 31, 1998. Apparent occupancy (occupant sensor data) for the same data set is shown with gray bars. The apparent occupancy includes the occupant sensor time delays and therefore overestimates actual occupancy.

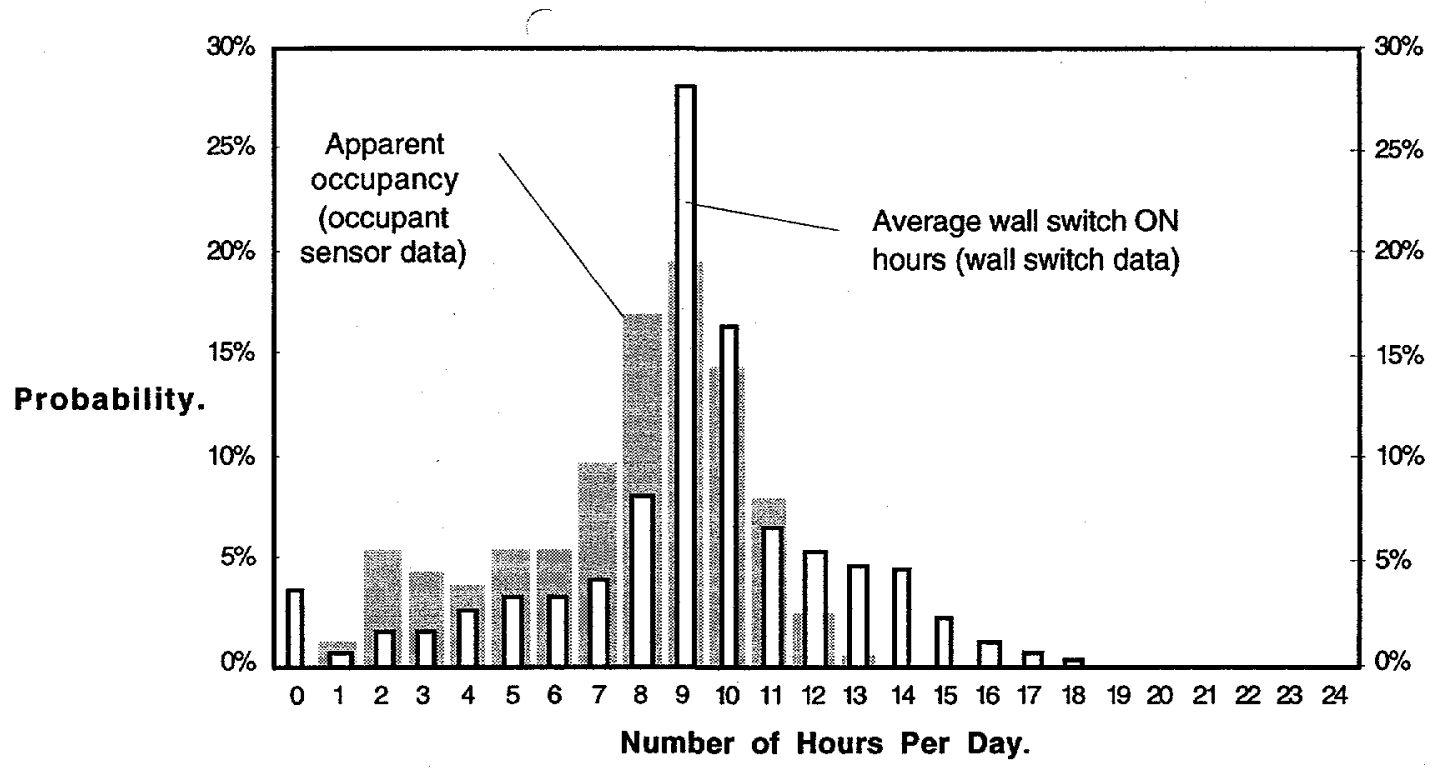

Figure 10. Average lighting $O N$ hours per day (calculated from the wall switch data) for 14 offices on the $5^{\text {th }}$ floor for occupied days between June 1 and December 31, 1998. Apparent occupancy (occupant sensor data) for the same data set is shown with gray bars. The apparent occupancy includes the occupant sensor time delays and therefore overestimates actual occupancy. 




Figure 11. Average lighting $O N$ hours per day for the $145^{\text {th }}$ floor offices (both occupant sensor and switch $O N$ ) for occupied days between June 1 and December 31, 1998. Apparent occupancy (occupant sensor data) for the same data set is shown with gray bars. The apparent occupancy includes the occupant sensor time delays and therefore overestimates actual occupancy.

\section{Light Level Adjustment--Switching}

\section{Bi-level switching}

Figure 12 gives the results of the analysis of the bi-level switching on the base case floor for seven months (June - December 1998). Note that while 19 occupants (63\%) use mostly full lighting (all three lamps), 4 (13\%) used mostly $2 / 3$ lighting (outer two lamps) and 7 (23\%) tend to use only $1 / 3$ (inner lamp). Furthermore, the data indicate that these light levels are chosen consistently for each room, demonstrating that a significant fraction of the occupants in this sample use the bi-level switches consistently to choose less-than-full lighting. Even those occupants who usually use full lighting occasionally use only one switch for the entire day. The inset in Figure 12 shows the percentage of total lighting hours in this sample at each light level. $45 \%$ of the lighting zone-hours were at less than. full lighting, with $28 \%$ at only $1 / 3$ lighting. 


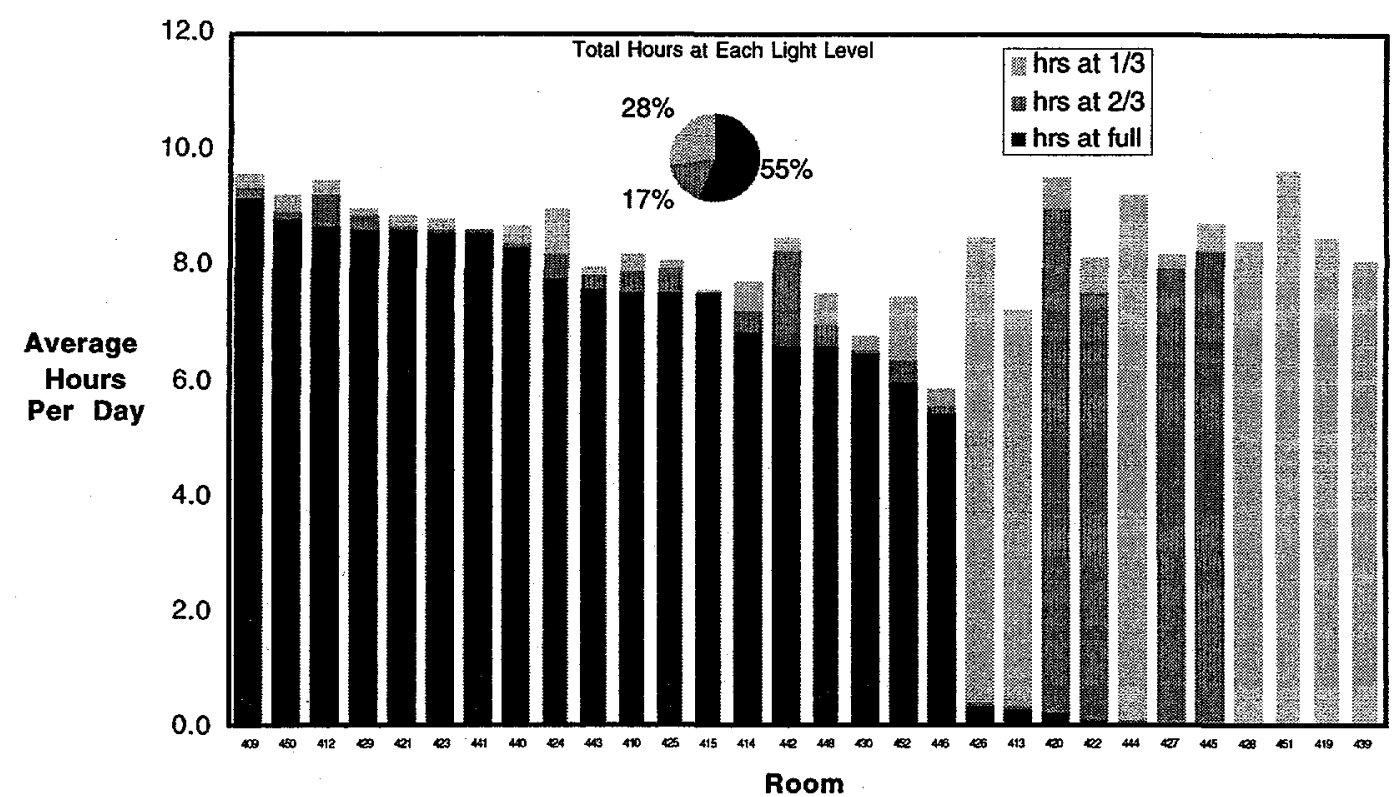

Figure 12. Average hours per day that the lights were at $1 / 3,2 / 3$ or full lighting for 30 private daylit offices on the $4^{\text {th }}$ floor. Data are for 2838 occupied office-days between June 1 and December 31, 1998.

We found that the lights were on (at any light level) for an average of $8.7 \mathrm{hr} /$ day, with full lighting averaging 4.9 hours, $2 / 3$ lighting averaging 1.6 hours and 1/3 lighting averaging $2.1 \mathrm{hr} /$ day. Note that even in the absence of occupant sensors the average daily lighting hours for this base case floor is very close to the measured wall switch ON hours ${ }^{6}$ for the $3^{\text {rd }}$ floor $(8.7 \mathrm{hr} /$ day $)$ and $5^{\text {th }}$ floor $(8.9 \mathrm{hr} / \mathrm{day})$. In other words, it appears that the occupants' switching behavior is not affected by the presence of occupant sensors. However, the actual measured lighting ON hours per day (both light switch and occupant sensor ON) are significantly lower for the $3^{\text {rd }}$ and $5^{\mathrm{th}}$ floors (6.7 and $6.8 \mathrm{hr} /$ day). As mentioned earlier, the cleaning crew is diligent about turning off lights on all three floors at night.

The overall savings attributable to bi-level switching over the 7 -month period amounted to about $33 \%$, The statistics for the fourth floor data are presented in Table 3 below.

\footnotetext{
${ }^{6}$ On the third and fith floors the measured wall switch ON hours are not usually equal to the measured lighting ON hours; if the switch is on and the occupant sensor is off, the lights are off.
} 
Table 3: Fourth Floor Lighting Data

\begin{tabular}{|c|c|c|c|c|c|c|c|c|c|}
\hline \multirow[t]{2}{*}{ Zone } & \multirow{2}{*}{$\begin{array}{c}\text { No. of } \\
\text { days }\end{array}$} & \multicolumn{2}{|c|}{ Hours at Full Light } & \multicolumn{2}{|c|}{ Hours at $2 / 3$ Light } & \multicolumn{2}{|c|}{ Hours at $1 / 3$ Light } & \multicolumn{2}{|c|}{ Hours Lights off } \\
\hline & & Average & Std. Dev. & Average & Std. Dev. & Average & Std. Dev. & Average & Std. Dev. \\
\hline 409 & 95 & 9.13 & 205 & 0.19 & 0.49 & 0.25 & 0.50 & 14.16 & 2.07 \\
\hline 410 & 86 & 7.51 & 1.62 & 0.30 & 0.97 & 0.37 & 0.63 & 15.55 & 129 \\
\hline 412 & 103 & 8.63 & 3.28 & 0.61 & 1.92 & 0.18 & 0.41 & 14.31 & 2.66 \\
\hline 413 & 115 & 0.27 & 1.00 & 0.08 & 0.33 & 6.83 & 2.70 & 16.55 & 2.54 \\
\hline 414 & 75 & 6.78 & 3.04 & 0.37 & 1.51 & 0.51 & 1.12 & 16.08 & 2.58 \\
\hline 415 & 41 & 7.45 & 2.18 & 0.05 & 0.22 & 0.10 & 0.30 & 16.14 & 2.15 \\
\hline 419 & 94 & 0.00 & 0.00 & 0.04 & 0.19 & 8.41 & 1.75 & 15.29 & 1.68 \\
\hline 420 & 120 & 0.19 & 1.02 & 8.75 & 3.01 & 0.53 & 1.27 & 14.26 & 2.31 \\
\hline 421 & 98 & 8.61 & 2.26 & 0.06 & 0.24 & 0.11 & 0.32 & 14.95 & $2: 22$ \\
\hline 422 & 84 & 0.09 & 0.39 & 7.42 & 1.83 & 0.58 & 0.98 & 15.64 & 1.58 \\
\hline 423 & 106 & 8.57 & 1.59 & 0.01 & 0.10 & 0.19 & 0.92 & 14.96 & 1.24 \\
\hline 424 & 102 & 7.73 & 1.69 & 0.43 & 0.57 & 0.79 & 0.62 & 14.77 & 1.95 \\
\hline 425 & 54 & 7.49 & 2.77 & 0.44 & 1.90 & 0.11 & 0.32 & 15.69 & 2.69 \\
\hline 426 & 34 & 0.32 & 1.36 & 0.08 & 0.27 & 8.02 & 2.40 & 15.31 & 1.40 \\
\hline 427 & 97 & 0.03 & 0.16 & 7.88 & 1.85 & 0.28 & 0.89 & 15.54 & 1.55 \\
\hline 428 & 106 & 0.02 & 0.14 & 0.01 & 0.07 & 8.38 & 2.14 & 15.33 & 2.14 \\
\hline 429 & 108 & 8.62 & 2.16 & 0.17 & 0.42 & 0.16 & 0.39 & 14.79 & 2.09 \\
\hline 430 & 119 & 6.42 & 2.75 & 0.13 & 0.33 & 0.18 & 0.41 & 16.99 & 2.69 \\
\hline 439 & 101 & 0.00 & 0.00 & 0.05 & 0.21 & 7.99 & 1.72 & 15.70 & 1.66 \\
\hline 440 & 39 & 8.29 & 5.21 & 0.05 & 0.22 & 0.31 & 0.61 & 15.08 & 5.05 \\
\hline 441 & 79 & 8.52 & 1.52 & 0.06 & 0.25 & 0.03 & 0.16 & 15.12 & 1.40 \\
\hline 442 & 82 & 6.61 & 3.03 & 1.65 & 2.89 & 0.17 & 0.38 & 15.30 & 1.54 \\
\hline 443 & 63 & 7.58 & 2.92 & 0.17 & 0.46 & 0.17 & 0.38 & 15.79 & 2.79 \\
\hline 444 & $\pi$ & 0.04 & 0.19 & 0.06 & 0.57 & 9.08 & 2.58 & 14.55 & 2.31 \\
\hline 445 & 72 & 0.02 & 0.15 & 8.23 & 2.53 & 0.47 & 121 & 15.01 & 2.14 \\
\hline 446 & 31 & 5.42 & 3.53 & 0.13 & 0.34 & 0.32 & 0.65 & 17.86 & 3.17 \\
\hline 448 & 88 & 6.57 & 3.10 & 0.36 & 1.26 & 0.58 & 1.75 & 16.22 & 2.85 \\
\hline 450 & 74 & 8.77 & 3.59 & 0.15 & 0.43 & 0.30 & 0.57 & 14.52 & 3.51 \\
\hline 451 & 100 & 0.01 & 0.10 & 0.00 & 0.00 & 9.64 & 1.54 & 14.09 & 1.51 \\
\hline 452 & 84 & 5.97 & 3.81 & 0.36 & 1.31 & 1.08 & 222 & 16.33 & 3.25 \\
\hline Total & 2527 & 4.69 & 4.37 & 1.40 & 3.10 & 2.32 & 3.71 & 15.32 & 2.42 \\
\hline
\end{tabular}




\section{Light Level Adjustment--Dimming}

Our earlier analysis of occupancy data ignored the additional energy-saving effects of dimming. Figure 13 consists of graphs of occupancy, wall switch, and energy data for four representative perimeter offices, one in each of the four dimming modes (task tuning, manual dimming, direct closed-loop daylighting, it closed-loop daylighting).
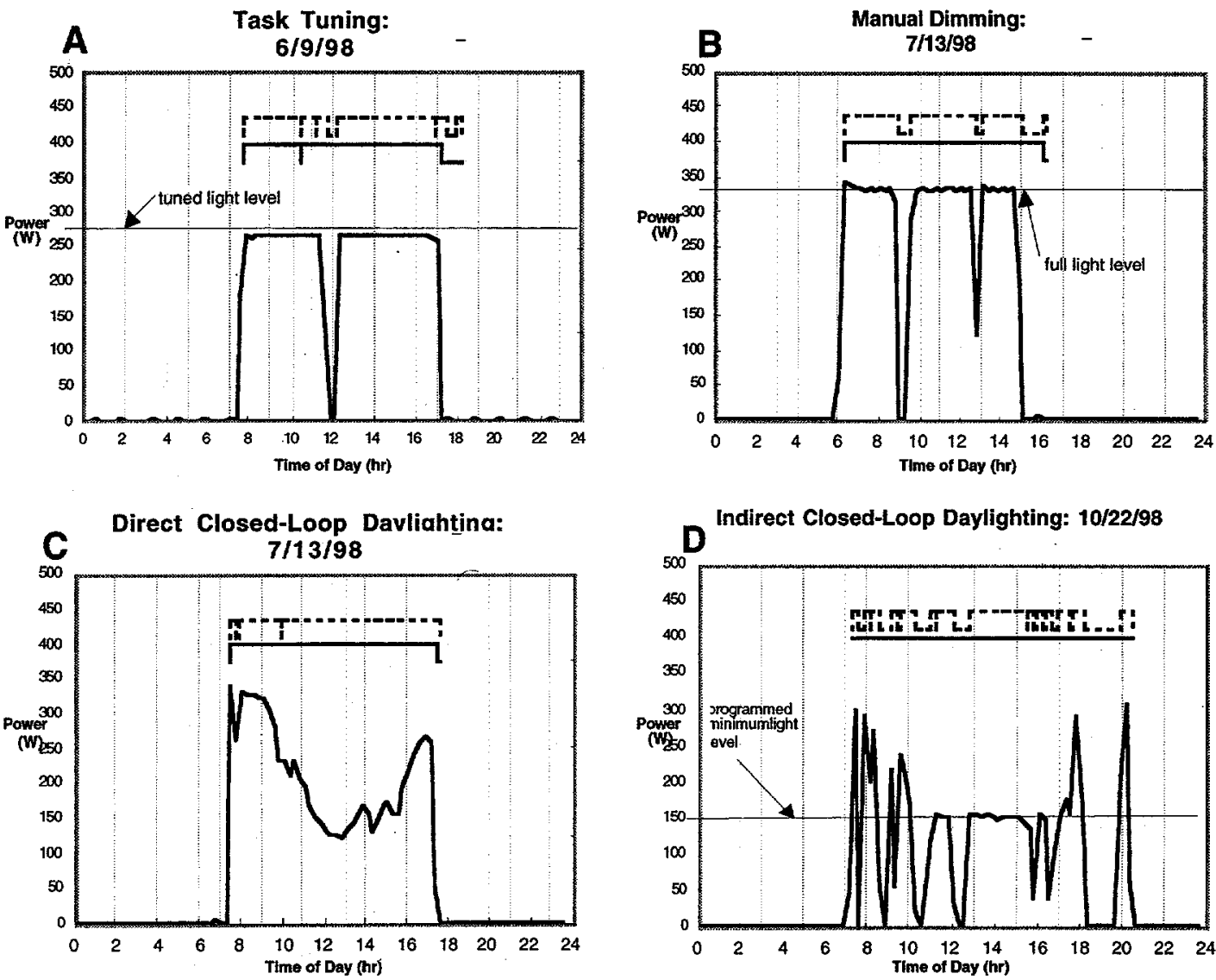

Enerov Data

Wall Switch Data

Occupant Sensor Data

Figure 13. Lighting power, wall switch data and occupant sensor activity as a function of time of day for four same-sized offices using four different dimming scenarios. (A) shows task tuning for a day in June, (B) shows no reduction in lighting power for a room equipped with manual dimmer in June, (C) shows change in lighting power as more daylight enters space during middle of day in July, (D) shows how both daylight dimming and occupant sensor activity affect the lighting power over this day in October 1998.

The shape of the each energy curve in each graph in Figure 13 is characteristic of the type of dimming control technique that is used in that area. All four examples have the same installed wattage. Varying degrees of occupant sensor activity, passing clouds, or shadows/reflections from neighboring buildings show up as spikes in the energy data, but it is the shape of the underlying curve that is of interest in this figure. For the task tuning example (Fig. 13A) the energy curve is lower than on the manual dimming example (Fig. 13B), but both curves are essentially flat while the lights are on, because there is no dynamic dimming taking place during the day. In the direct closed-loop daylighting example (Fig. 13C), the energy curve is basically sinusoidal, with the energy use from the electric lights changing in direct response to with varying amounts of daylight coming into the space. The low point of the curve for this dimming technique is purely a function of the amount of available daylight, limited only by the ballast minimum output $(-20 \%$ power $)$. 
The indirect closed-loop daylighting example, Figure 13D, shows a flat area at the bottom of the energy curve, indicating that the minimum programmed light output was reached and further dimming was prevented. (For this last example, the minimum was set rather high because of the occupant's visual needs. Other possible variations on the dimming protocol are possible by modifying the dimming algorithm in the distributed control system). The ability to control and set the minimum light level is an example of the flexibility of the distributed control system. If the light sensor were wired directly to the ballasts' low-voltage control leads, the minimum light level would be determined solely by the ballast characteristics.

Figure 13D is particularly interesting in that it shows the superimposed effect of daylight dimming and occupant sensing on the electric lighting power usage. Graphs showing the successful integration of daylighting and occupant sensing in private offices have not been reported elsewhere. This figure provides evidence that advanced lighting control techniques that combine several control strategies simultaneously can work well in private offices.

Figures 14,15 , and 16 show the average energy use by zone under three of the four dimming scenarios, derived as described in Methods. The first column in each graph shows the energy use that would have occurred with the occupant sensor as the only control method. The second column shows the energy use with dimming alone, and the third column shows the actual energy use with both occupant sensing; and dimming (all three columns assume a wall switch).

These three graphs illustrate the fact that the actual energy savings one obtains depends largely on how individuals use their offices. The relative heights of the columns indicate which control technique is primarily responsible for energy savings. For example, in offices where occupancy is low (low "os only" column), the occupant sensor is the most important factor in energy savings. For offices where occuplancy is particularly high (high "os only" column), the dimming, regardless of method, has the greatest influence on energy use.

The difference between the first and third columns ("os only" vs. "os + dimming") is a measure of the energy savings achieved by dimming in the presence of occupant sensors. Figure 15 shows a small amount of savings due to dimming. These dimming savings in all three graphs are probably also influenced by the discreteness of the energy data, which is available only in 15-minute intervals.

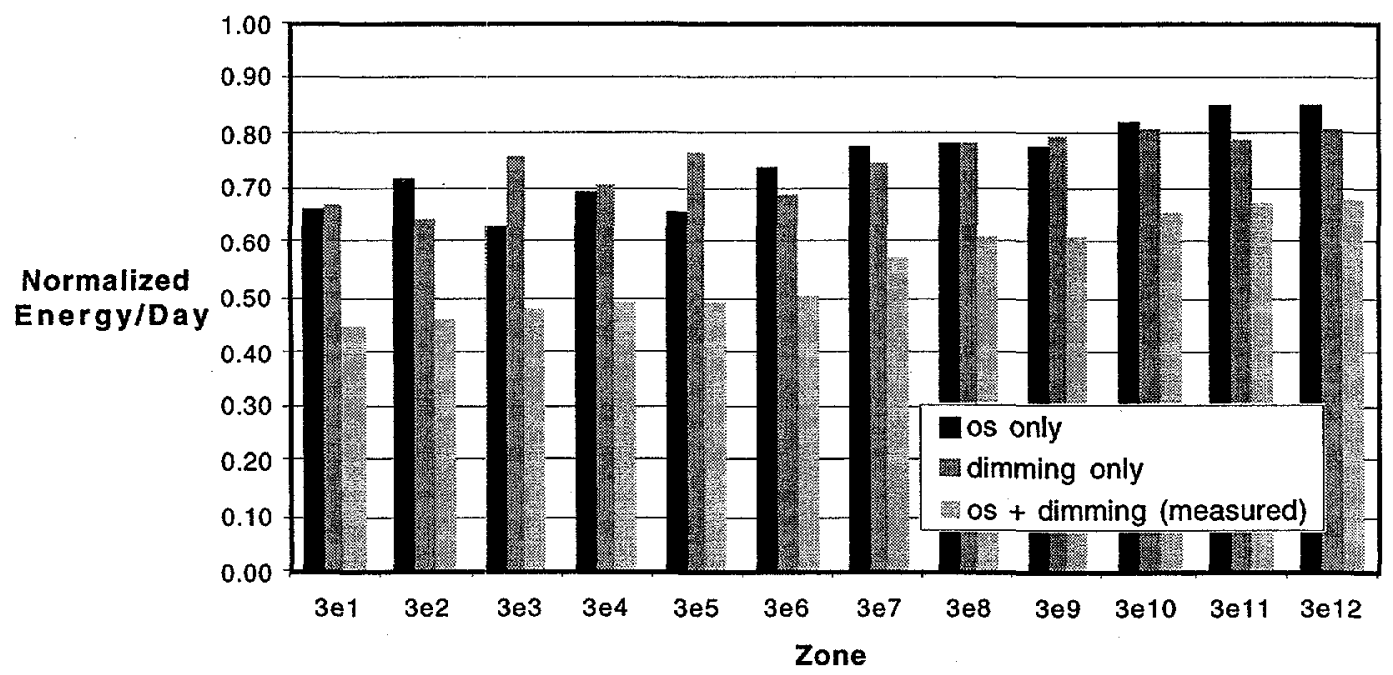

Figure 14. Average normalized lighting energy use for 12 private offices on the $3^{\text {rd }}$ floor East (Task Tuning) for occupied weekdays for the month of July 1998. Energy use per day with wall switch only $=1.0$. 


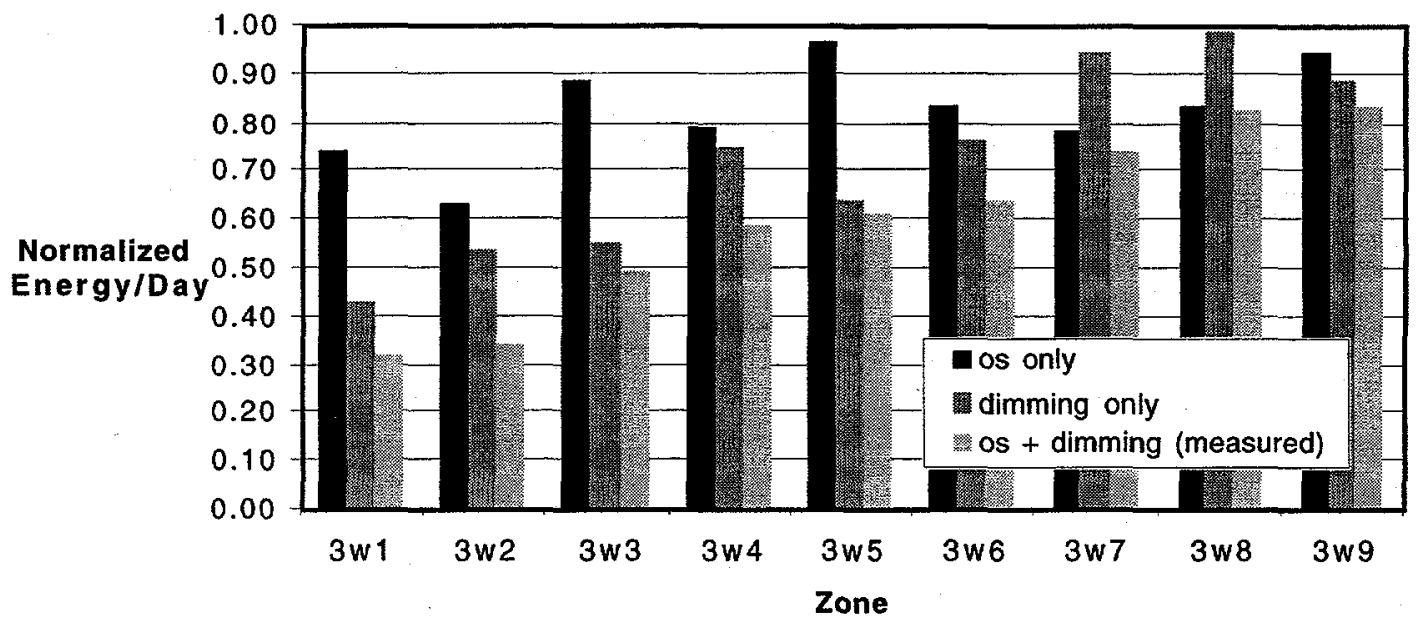

Figure 15. Average normalized lighting energy use for 9 private offices on the $3^{\text {rd }}$ floor West (Manual Dimming) for occupied weekdays for the month of July 1998. Energy use per day with wall switch only $=1.0$.

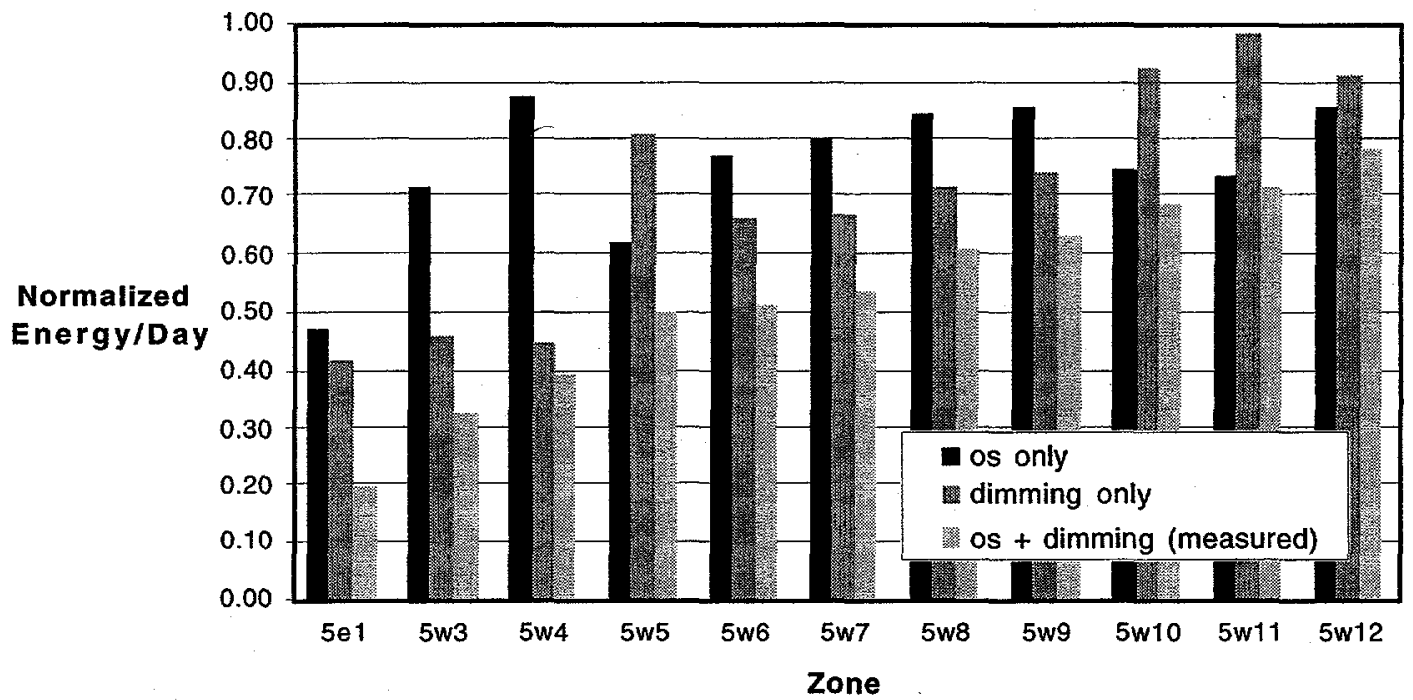

Figure 16. Average normalized lighting energy use for 11 private offices on the $5^{\text {th }}$ floor West (Automatic Daylighting) for occupied weekdays for the month of July 1998. Energy use per day with wall switch only $=1.0$.

For comparison, the energy use due to four control strategies is presented in Table 4 . The three columns are calculated as for Figures 14, 15, and 16.

Table 4. Energy Use Comparison Using Different Control Strategies

\begin{tabular}{|l|c|c|c|c|}
\hline $\begin{array}{c}\text { Light Level } \\
\text { Adjustment Method }\end{array}$ & os only & $\begin{array}{c}\text { light level } \\
\text { control } \\
\text { only }\end{array}$ & $\begin{array}{c}\text { os }+ \\
\text { dimming } \\
\text { (actual) }\end{array}$ & $\begin{array}{c}\text { dimming } \\
\text { target }\end{array}$ \\
\hline Task Tuning (3 east) & 0.74 & 0.74 & 0.55 & $50 f c$ (550lux) \\
\hline Manual Dimming (3 west) & 0.82 & 0.72 & 0.60 & $\mathrm{n} / \mathrm{a}$ \\
\hline Daylighting (5 west) & 0.76 & 0.72 & 0.56 & $75 \mathrm{fc}$ (825lux) \\
\hline Bi-Level Switching & $\mathrm{n} / \mathrm{a}$ & $\begin{array}{c}0.77 \\
\text { (actual) }\end{array}$ & $\mathrm{n} / \mathrm{a}$ & $\mathrm{n} / \mathrm{a}$ \\
\hline
\end{tabular}


The third column of Table 4, occupant sensing in conjunction with dimming, gives the actual energy saved by each dimming scenario studied. Note in the last column of Table 4 that the dimming target is not the same for the different dimming methods. The dimming target has a significant effect on the energy savings achieved, so it is important to take it into consideration when comparing the numbers in the rest of the table. Had the dimming target in $5 \mathrm{w}$ been the same as the much lower target in in the third floor (east), the savings in the fifth floor west would have been considerably greater.

The effect of the design light level can also be seen in Figure 13, where we did include the one office that survived our filters. In Figure 13, the low point of the energy curve in 5 east is not limited by a preset minimum as is the low plateau of the energy curve in 5 west. (The two charts can only be compared for the shape of the curve, because their data was recorded on different days.)

Bi-level switching is included in the table for comparison purposes. We found savings of $77 \%$ from this method.

\section{Task Tuning}

In the Phillip Burton Federal Building, it was possible to achieve very significant energy savings simply by tuning the lighting level. Table 4 shows that, used alone, dimming and occupant sensing each save about the $26 \%(1.0-0.74=0.26)$ in the task tuning area. Together, (occupant sensing plus dimming) the savings was $45 \%$. Figure 11 shows this effect in the comparison between the east (tuned) and west halves of the third floor. Had the building used a more appropriate light level in the original lighting design, such a large savings due to task tuning alone would not have been possible. However, it is fairly common practice to locate $2 \mathrm{X} 4$ parabolic troffers into office ceilings on an $8 \mathrm{ft}$. grid to minimize design effort and to accommodate the changing needs of typical offices, so savings from task tuning would be possible in many office spaces if the ballasts were dimmable.

\section{Manual Dimming}

For the area equipped with manual dimmers, Table 4 indicates savings of $23 \%$ by dimming alone and $40 \%$ by occupant sensing with dimming. Maniccia [2] found $9 \%$ savings due to manual dimmers when the manual dimmers were located on desktops as well as on the wall using a fixed baseline. In that study the dimmers were in place for a much shorter period, possibly affecting the occupants' awareness of/interest in them. In the current study, the manual dimmers were installed in the offices before the occupants moved in, and the occupants were not instructed in their use. When the occupants first moved in, they showed some interest in the manual dimmers (based on their comments and our observations), but by the time the system had been in place for over a year there was little significant dimming activity taking place.

It is possible that people would have used their manual dimmers differently had it been possible to adjust the light levels from their desks, either by desk-mounted dimmers as in the Maniccia study or by handheld remote dimmers. Hand-held remote dimmers are installed in a sample of zones in the testbed, but their use is not covered in this paper.

Figure 17 shows the fraction of total hours between 6 am and $6 \mathrm{pm}$ where occupants appeared to have their dimmers set at various fractions of full output. The accuracy of this figure is limited by the 15minute intervals of energy data collection. Nevertheless, we can make some preliminary observations. The large fraction (53\%) of hours at zero probably bespeaks the large amount of time the individual offices are unoccupied, although some of those hours may be due to individuals working without lights (see Figure 7, for example). During most hours in which lights were used at all, they were used at more than $90 \%(.9-1.0)$ of full power ( $21 \%$ of all hours between 6 am and $6 \mathrm{pm}$, or $21 / 47$ or $49 \%$ of "on" hours in the same period). Similarly, lights were apparently used at $80-90 \%$ of full power for $6 / 47$ or $13 \%$ of all "on" hours, and at $70-80 \%$ of full power for $5 / 47$ or $11 \%$ of all "on" hours. For all remaining power levels, the values are very low, and are probably distorted by the 15 -minute data collection interval as well as the occupant sensor delay. More data are being collected on this control method in order to clarify these results. 


\section{Number of Hours at Different Lighting Levels: Manual Dimming Zones}

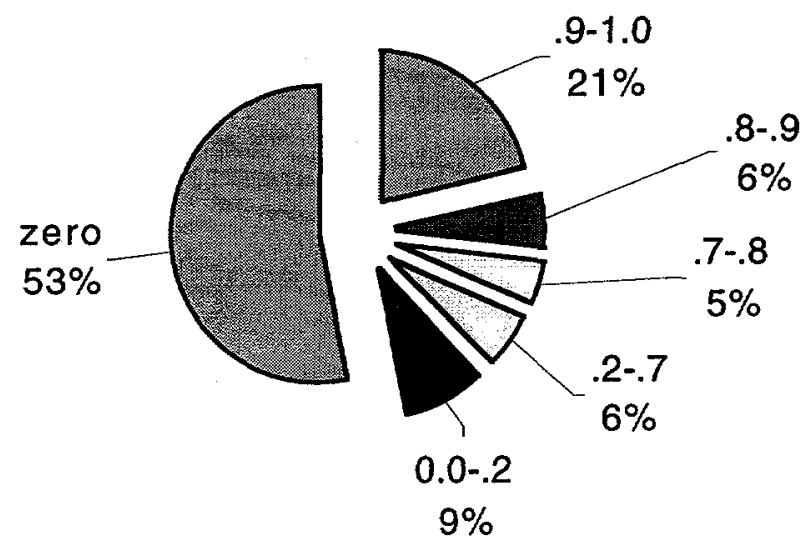

Figure 17. Percentage of total occupied hours at different lighting levels in 14 zones equipped with manual slide dimmers. Occupied hours were determined by occupant sensor activity.

\section{Daylighting}

In the daylighting areas dimming seems to save more than occupant sensing ( $28 \%$ dimming vs. $18 \%$ occupant sensing for the manual dimming area, and $28 \%$ dimming vs $24 \%$ occupant sensing in the daylighting area). as in the manual dimming areas, the daylighting results from the $5^{\text {th }}$ floor show savings of $28 \%$ from dimming alone, and the savings is a $44 \%$ savings from occupant sensing plus dimming. These numbers are strongly affected by the dimming target given in Table 4 . The savings would be significantly greater in the daylit areas had the dimming target been as low as that in the task tuning area.

\section{DISCUSSION}

Our results indicate that occupant sensors save an average of $20-23 \%$ of lighting energy in private offices at this installation. This savings were determined relative to a moving baseline that reflects an accurate calculation of what the lighting hours would have been had the lights been operated only by the wall switch. Because occupancy varies from day to day, the energy savings due to occupant sensing on a given day can easily range from $0-40 \%$. But on average the occupant sensor reduced the lighting ON hours from about 9 hours per day without the occupant sensor to about 7 hours with the sensor.

The frequent occurrence of the $0 \%$ energy savings days in the occupant sensor analysis deserves more comment. There are several circumstances that can cause such days. By examining the data from individual days, it is clear the preponderance of the $0 \%$ days occur when the occupant working in his/her office apparently does not leave during the day for periods longer than the occupant sensor delay, so that the occupant does not switch off the lights. About $10 \%$ of days on the third floor and about $6 \%$ of days on the fifth floor fit this category. In addition, occasionally occupants will work the entire day without using overhead lights at all. Days in this category have no energy savings (from either occupant sensing or light level reduction) simply because the occupant would not have used any energy regardless of the control system. This seems to occur $4-7 \%$ of the time. People have been observed working in daylit offices without overhead lights [1],[2], and informal comments by the occupants in this study indicate that they do work sometimes without their overhead electric lights.

Although the occupants can, and usually do, switch off the lights manually when leaving at the end of the day, the occupant sensor will switch the lights off 15-20 minutes afterward should they forget. We cannot refute or confirm the claim [1] that people working without occupant sensors tend to be more frugal about leaving lights on when leaving their office for short time periods than people with occupant sensors. However, based on our observations of the switching patterns of the base case floor, it does not 
appear that the occupants of this building turn off their overhead lights when leaving the office for short time periods during the day.

The use of bi-level switching by the occupants of the base case floor was unexpected and has not been reported elsewhere. Pigg [1] reported very little use of bi-level switching in their installation. It is reasonable to assume that the presence of daylight in these offices had an influence as to which of the four possible light levels was selected by the occupants. However, an initial examination of the data revealed no correlation of the data with the orientation of the offices.

The tendency to work at lower-than-full lighting levels is also apparent in the offices on the third floor that were equipped with manual dimmers. Wall-mounted dimmers may be less convenient to use than dimmers located on the desktop as in a previous study [2]. We can speculate that manual dimming and switching results might have been affected by the presence or absence of task lighting; preliminary survey results appear to show such an effect.

Arguably the most convenient of the dimming options, automatic daylighting shows similar savings to task tuning and manual dimming even with a much higher dimming target. Clearly the savings from this method would have been much greater had the dimming target been set at the same level as for the third floor offices. On the other hand, the programmable output in these offices allowed us to tune the output to the specific lighting needs of the occupants in this area, an added user benefit that should not be overlooked (see "Office Culture" below).

So why were the switching and manual dimming controls used differently in some areas than in others? Wyon reminds us that there are three essential elements that people need to use controls effectively: information, insight, and influence. Information to let the occupants know that the control systems exist, and how to operate them. The insight as to why the occupant might want to use them and what the benefits are. And lastly, influence: the occupant must have the means to influence the system in question. In this testbed the influence was present in the form of the controls themselves (in two of the areas the occupants could manipulate the light levels themselves); but the first two were significantly lacking. In hindsight, had the occupants been given more information and insight into the lighting controls from the start, the results from the manual dimming controls might have been different.

Workers who stay in their offices all day long stand to benefit the most from dimming strategies, while those who come in and out of their offices frequently make the best use of occupant sensors as energy saving devices. On the whole, dimming can add significantly to the savings achieved by occupant sensing, saving $29 \%$ even without occupant sensing and $43 \%$ with occupant sensing. As noted above, manual dimming using wall dimmers provided little significant savings in our sample. We have yet to determine whether or not better instructions in their use would have affected this result. [this result will be based on the full 7-month data set for the final draft]. Our results differ from previous work [2], which we propose is due at least in part to a different type of occupant, and in part to the length and methodology of the study. The previous study [2] used university workers as subjects and each different lighting control system was only left in place for 2-3 weeks at a time before changing treatments. In the current study, the government employees who were the subject of the study had months, if not years, to acclimate to the new technology. Consequently, it is unlikely that the novelty of the controls played any role in the occupants' behavior with respect to the occupant sensors or manual dimmers.

We have observed that some occupants of our testbed tend to work regular hours, while others keep very unpredictable hours based on their project deadlines or case load. Also, many occupants of private offices do not spend a lot of time in their offices, and the tendency to be out of the office seems to correlate with the type of work that they do.

The two daylighting systems we examined differed primarily in the ability to program the response of the ballasts through a remote system. Depending on the needs of the building occupants, the programmable system could save more or less energy than the directly controlled system. It is more intellectually challenging to set up the programmable system, as well as being more costly in wiring and commissioning, but it has additional benefits that mitigate the extra expense. For example, the ability to adjust the lighting levels from a remote location in response to an occupant's request can save building maintenance staff considerable time in responding to complaints. 


\section{Office culture}

Working groups in GSA, as in most organizations, tend to be clustered in one part of the building or another. This arrangement facilitates communication between team members, but concentrates islands of occupant behavioral patterns according to the particular type of tasks performed. We have noticed, for example, that in the part of the building where the GSA attorneys sit, the lighting level must be set higher than in other parts of the testbed. When in their offices, attorneys work long hours reading documents that are in fine print, have been faxed, or are simply old and deteriorated. In contrast, graphic designers use computers and prefer lower light levels to keep glare at a minimum. Some types of job require the occupant to be out of the office frequently, while others require more desk time. These differences make it difficult to compare different areas of the test bed against each other. The use of the moving baseline we have described has largely eliminated this difficulty with respect to occupancy, but the differences in light level requirement are more difficult to analyze. Because this is a working building, we chose to accommodate the needs of the building occupants by giving them the light levels they required, which varied according to the type of work they were doing, rather than adhering to a rigid experimental protocol.

The building management and support personnel have a significant affect on the way the occupants use their lighting controls. In the Phillip Burton building, the building manager at the time of the startup of the experiment had been very active in encouraging his staff and the building occupants to shut off their lights when they leave an area. As a result, the savings from occupant sensing may be somewhat lower than would be seen in other buildings.

\section{CONCLUSION}

In a major test of different lighting control technologies in a typical office building, we compared the energy savings and effectiveness of various control techniques in private offices. Using a rigorous analytical method that compared measured energy use in offices with occupant sensors against baseline use calculated using wall switch operation only, we found that occupant sensors saved $18-24 \%$ lighting energy compared to manual switching alone. These savings occur because of intermittent vacancies throughout the day. In offices where light sensor controls were installed, additional savings up to $20 \%$ were obtained over a seven-month period if the daylighting controls were properly commissioned, even in an area with unusually high minimum lighting requirements. Dimming the lighting system to desired task levels (task tuning) also resulted in significant (19\% additional) energy savings in overlit areas. On the base case floor, where only bi-level switches were installed, we found significant usage of only one switch resulting in an additional 10\% savings over occupant sensing alone-- an unexpected result with implications for building code requirements.

We found that the energy savings due to occupant sensing vs. dimming depended on the behavior of occupants. In offices whose occupants tended to stay at their desks all day, dimming controls saved more energy, and vice versa. The lighting requirements of occupants appear to depend on their type of work.

Including the effects of switching, occupant sensing, and light-level reduction controls, the four scenarios for which we had significant data yielded $23 \%$ savings for bi-level switching alone, $45 \%$ savings due to occupant sensing with task tuning, $40 \%$ savings from occupant sensing with manual dimming, and $44 \%$ savings from occupant sensing with automatic daylighting controls. The savings from automatic daylighting are comparatively low for this study because of the high light levels required by the occupants of the particular office area studied.

\section{ACKNOWLEDGMENT}

This work was supported by the General Services Administration, Pacific Rim Region; the Pacific, Gas \& Electric Co.; and the Assistant Secretary for Energy Efficiency and Renewable Energy, Office of Federal Energy Management Programs and by the Office of Building Technology, State and Community Programs, Office of Building Equipment of the U.S. Department of Energy under Contract No. DEAC03-76SF00098. Each of the aforementioned project sponsors has contributed considerable support to the goal of improving energy efficiency in Federal properties. We would also like to thank John Rigdon, Laura McLaughlin, Helen Lam, and Rachna Nivas for their tireless legwork and data handling efforts. We particularly acknowledge the support of GSA's Peter Gaddy, Terry Pierce, Warren Sitterley and Beth Shearer whose cooperation and support made this project possible. 


\section{REFERENCES}

1. Pigg S, Eilers M, Reed R. "Behavioral Aspects of Lighting and Occupancy Sensors in Private Offices: A Case Study of University Office Building," Proceedings of the 1996 ACEEE Summer Study on Energy Efficiency in Buildings, Vol. 8, pp. 8.161-8.171, 1996.

2. Maniccia D, Rutledge B, Rea M, Morrow W. "Occupant Use of Manual Lighting Controls in Private Offices," Proceedings of the 1998 Annual Conference of the IESNA, August, 1998.

3. Richman E, A Dittmer, J.M. Keller. "Field Analysis of Occupancy Sensor Operation: Parameters Affecting Lighting Energy Savings". Journal of the IESNA, Winter, 1996.

4. Rubinstein F, Jennings J, Avery D, Blanc S. "Preliminary Results from an Advanced Lighting Controls Testbed," Journal of the IESNA, Winter, 1999.

5. Rubinstein F, Ward G, Verderber R (1989). "Improving the Performance of Photo-Electrically Controlled Lighting Systems," Journal of the IESNA, Winter, 1989.

6. Love J. "Field Performance of Daylighting Systems With Photoelectric Controls," Proceedings of the $3^{\text {rd }}$ European Conference on Energy Efficient Lighting, Newcastle upon Tyne, England, June 1995.

7. Rubinstein F, Siminovitch M, Verderber R. " $50 \%$ Energy Savings with Automatic Lighting Controls," IEEE-IAS Transactions on Industry Applications, 1991.

8. Verderber, R, Rubinstein F. "Lighting Controls: Survey of Market Potential," Energy, Vol. 8, No. 6, pp. 433-449, 1983.

9. Reed J, Pinkowski C, Mapp J, White S, Hall N, Caldwell B. "Lessons From a Daylighting Retrofit: A Case Study of a Building," Wisconsin Demand-Side Demonstrations Report, May 1995.

10. US Department of Energy. "Adyanced Lighting Guidelines: 1993," DOE/EE-0008, Office of Building Technologies, Washington DC, 1993. 